\title{
Photo-conjugation of an Fc-specific peptide enables efficient DAR 2 antibody-drug conjugate formation
}

TaeJin Lee ${ }^{1,2, a}$, Ju Hwan Kim²,a, Se Jeong Kwon ${ }^{1,2}$, Sun Hee Park ${ }^{1,2}$, Jinyoung Kim ${ }^{3}$, Hyo Jin

$$
\mathrm{Kang}^{2} \text {, Sang J. Chung }{ }^{1,2^{*}}
$$

${ }^{1}$ School of Pharmacy, Sungkyunkwan University, Suwon 16419, Republic of Korea

${ }^{2}$ AbTis Co. Ltd. A-815, Suwon Venture Valley II, 142-10, Saneop-ro 156beon-gil, Gwonseongu, Suwon-si, Gyeonggi-do 16648, Republic of Korea

${ }^{3}$ Biocenter, Gyeonggi-do Business and Science Accelerator, Suwon, 16229, South Korea

a These authors contributed equally to this work.

*Corresponding author. E-mail address: sjchung@ @kku.edu

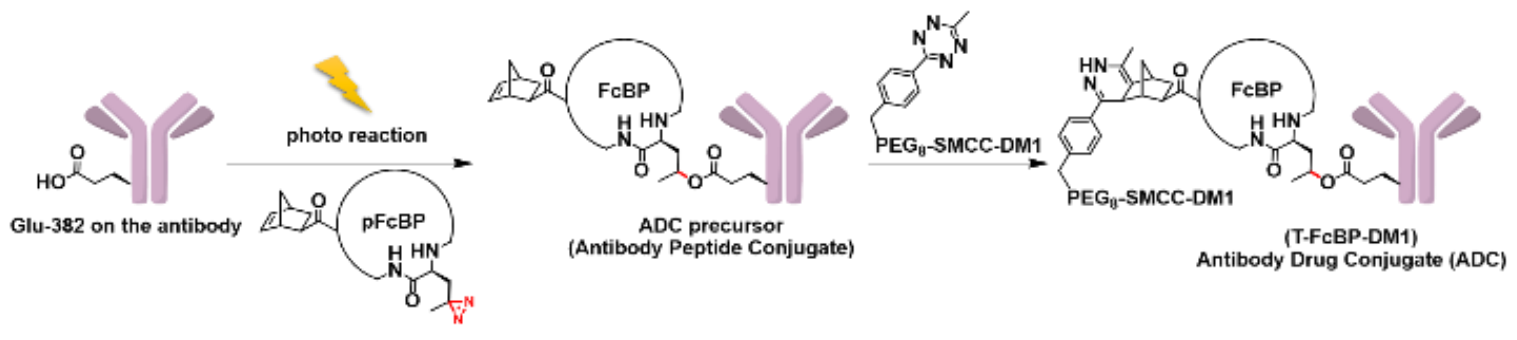




\section{Table of contents}

1. Materials and equipment.

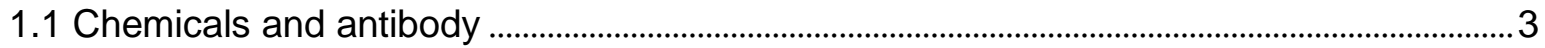

1.2 Characterization and purification of small molecules and peptides ........................................

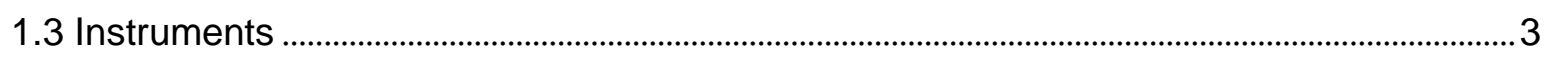

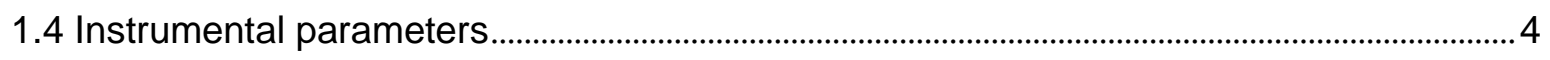

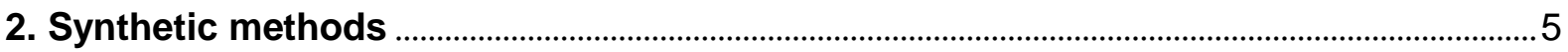

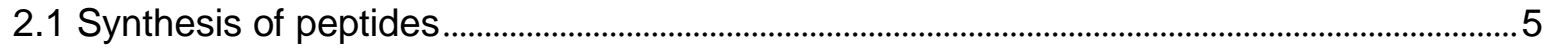

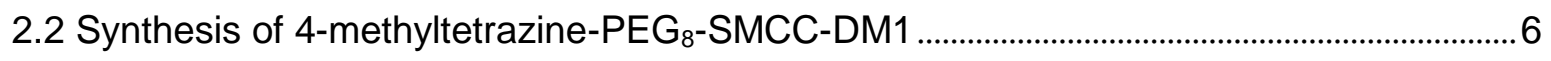

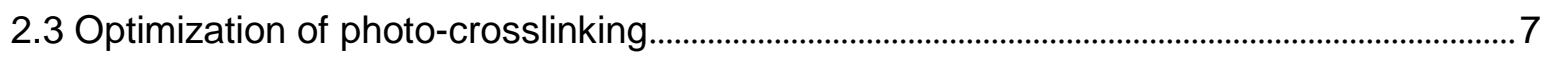

2.4 Purification of peptide-antibody conjugate with PAR 2 ….................................................... 8

2.5 Production of homogeneous ADC .................................................................................. 8

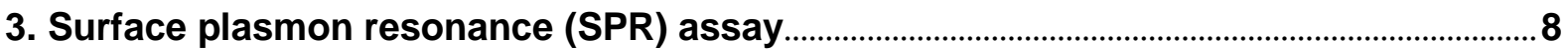

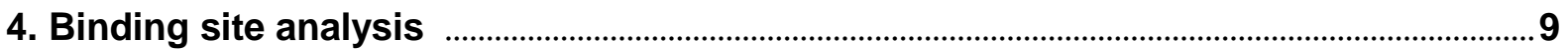

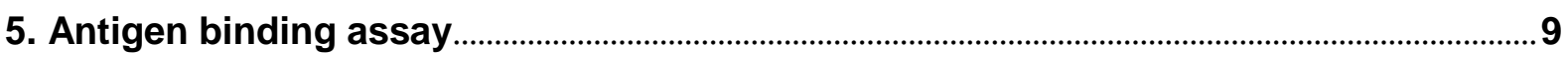

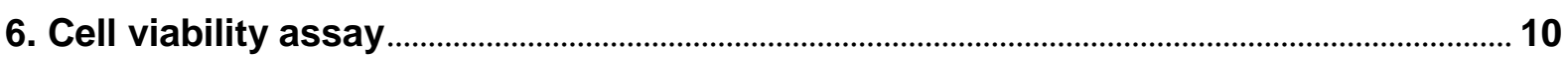




\section{Materials and equipment}

\subsection{Chemicals and antibody}

Chemicals were purchased from commercial suppliers and used without further purification. 5-exonorbornene carboxylic acid, (+)-biotin NHS ester, Ammonium sulfate $\left(\left(\mathrm{NH}_{4}\right)_{2} \mathrm{SO}_{4}\right)$, triisopropylsilane (TIS), and 1,2-ethanedithiol (EDT) were purchased from Sigma-Aldrich, 4-methyltetrazine- $\mathrm{NH}_{2}$ hydrochloride from Broadpharm Inc., Fmoc-PEG ${ }_{8}-\mathrm{OH}$ from Quanta Biodesign, Fmoc-L-pLeu-OH from Iris Biotech, and DM1-SMCC from eNovation Chemicals LLC. All amino acids, rink amide resin, and coupling reagents were purchased from Aapptec, GL Biochem Ltd. and Combi-Blocks. Solvents were used without distillation. Trifluoroacetic acid (TFA), N,N-diisopropylethylamine (DIPEA), diethylamine, $\mathrm{Na}_{2} \mathrm{HPO}_{4}, \mathrm{~N}, \mathrm{~N}$-dimethylformamide (DMF), dichloromethane (DCM), Methanol (MeOH) hexane (Hex), ethyl acetate (EA), and diethyl ether were obtained from Daejung (Korea). HPLC-grade acetonitrile (ACN), Isopropanol (IPA) and water were obtained from Fisherbrand ChemAlert. Trastuzumab (Herceptin) was purchased from Roche.

\subsection{Characterization and purification of small molecules and peptides}

Thin-layer chromatography was performed on pre-coated silica gel $F_{254}$ plates (Merck) and observed under ultraviolet light $(254 \mathrm{~nm})$ or by staining with $\mathrm{KMnO}_{4}$ or ninhydrin solutions. All synthesized compounds were purified by Combi-flash purification using prepacked silica gel cartridges. All synthesized peptides were purified by preparative-HPLC (Waters, with XBridge ${ }^{\mathrm{TM}}$ prep C $18,5 \mu \mathrm{m}, 4.6$ x $250 \mathrm{~mm}$ column).

\subsection{Instruments}

Centrifugation was performed with a Fleta 4 centrifuge (Hanil, Korea).

Photo-crosslinking was carried out using an XL-1000 UV Crosslinker from Spectrolinker ${ }^{\mathrm{TM}}$. All photocrosslinking reactions were performed at $365 \mathrm{~nm}$ for $20 \mathrm{~min}$.

All peptides and 4-methyltetrazine-PEG8-SMCC-DM1 were characterized using HPLC (Waters, XBridge $\left.^{\circledR}, \mathrm{C} 18,4.6 \times 250 \mathrm{~mm}, 5 \mu \mathrm{m}\right)$.

All antibodies including $\mathrm{pFcBP/trastuzumab}$ conjugates and ADC were characterized using HIC-HPLC (Thermo Scientific ${ }^{\mathrm{TM}}, \mathrm{MAbPac}^{\mathrm{TM}}$, HIC-butyl, $4.6 \times 100 \mathrm{~mm}, 5 \mu \mathrm{m}$ ).

Mass spectra of small molecules and peptides were obtained using electrospray ionization (ESI) and a time-of-flight (TOF) analyzer Quattro Premier XE mass spectrophotometer from Waters and a COSMOSIL COSMOCORE $2.6 \mathrm{C}_{18}$ column $(2.6 \mu \mathrm{m}, 2.1 \times 50 \mathrm{~mm})$.

Intact masses of all antibodies were obtained using matrix-associated laser desorption ionization and a time of flight analyzer (MALDI-TOF) with sinapinic acid (SA) as a matrix. MALDI-TOF mass spectra 
were acquired on an Ultraflex III mass spectrometer (Bruker Daltonics, Germany) equipped with a 337 $\mathrm{nm}$ pulsed nitrogen laser, operated in positive polarity and linear mode.

UPLC, NanoLC, and MS were used for the binding site analysis. UPLC-MS analysis of digested products was performed using an Orbitrap Fusion Tribrid (Thermo Fisher Scientific) coupled to a Waters Acquity UPLC and a Waters BEH C18 column $(1.7 \mu \mathrm{m}, 2.1 \times 100 \mathrm{~mm})$. NanoLC was coupled to an Orbitrap Fusion Tribrid (Thermo Fisher Scientific) via a continuous, vented column configuration.

SPR experiments were performed with carboxyl dextran CM- 5 gold chips on a Biacore T-200 device (GE Healthcare, USA) at $25^{\circ} \mathrm{C}$ using pH 7.4 TBS-T ( $0.05 \%$ Tween 20 containing Tris buffered saline) as a running solution.

\subsection{Instrumental parameters}

\section{Characterization of peptides and 4-methyltetrazine-PEG ${ }_{8}-S M C C-D M 1$ using HPLC}

HPLC was performed at a flow rate of $1 \mathrm{~mL} / \mathrm{min}$. All compounds were analyzed using the same elution condition, i.e., initial $80 \%$ mobile phase $\mathrm{A}\left(0.1 \%\right.$ TFA in $\left.\mathrm{H}_{2} \mathrm{O}\right)$ for 1 min followed by a $20-80 \%$ gradient of mobile phase $B(0.075 \%$ TFA in $A C N)$ in $A$ for $15 \mathrm{~min}$. The chromatogram of all peptides was acquired at $280 \mathrm{~nm}$ and 4-methyltetrazine-PEG8-SMCC-DM1 was acquired at $254 \mathrm{~nm}$.

\section{Characterization of pFcBP/trastuzumab conjugate using HIC-HPLC}

HIC-HPLC was performed at a flow rate of $1 \mathrm{~mL} / \mathrm{min}$. All antibodies were analyzed using the same

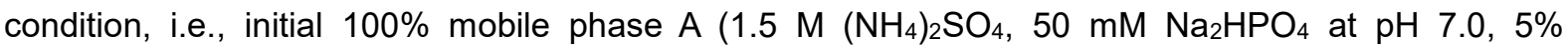
isopropanol) for $1 \mathrm{~min}$ followed by a $0-100 \%$ gradient of mobile phase $B(50 \mathrm{mM}$ sodium phosphate at $\mathrm{pH} 7.0,20 \%$ isopropanol) in A for $15 \mathrm{~min}$. All chromatograms were acquired at $280 \mathrm{~nm}$.

\section{Mass determination}

ESI-MS: The column temperature was set to $25{ }^{\circ} \mathrm{C}$ and a flow rate of $0.3 \mathrm{~mL} / \mathrm{min}$ was used. The compounds were injected into the column in volumes of $5 \mu \mathrm{L}$. Mobile phase A consisted of water with $0.05 \%$ TFA, while mobile phase $B$ consisted of acetonitrile with $0.05 \%$ TFA. The initial gradient condition was $20 \%$ B for $0.5 \mathrm{~min}$, then $\mathrm{B}$ was increased gradually to $80 \%$ in $3.5 \mathrm{~min}$, followed by the gradient decreasing from $80 \% B$ to $20 \% B$ in $0.1 \mathrm{~min}$.

Orbitrap Fusion Tribrid: The fragments from the antibodies were examined with an Orbitrap Fusion Tribrid mass spectrometer using a spray voltage of $+2.2 \mathrm{kV}$. A full scan from $\mathrm{m} / \mathrm{z} 300$ to 1,800 at a resolution of 120,000 was acquired. The top $N$ mode followed by a ten data-dependent acquisition of MS/MS scan method was applied using CID with a normalized energy of $35 \mathrm{eV}$. Dynamic exclusion of previously fragmented precursor ions was performed with the following parameters: exclusion after $n$ time 1, repeat duration $60 \mathrm{~s}$, exclusion mass width $10 \mathrm{ppm}$, and isolation width $1.6 \mathrm{~m} / \mathrm{z}$. Singly charged species were excluded from the fragmentation. 
MALDI-TOF: The antibodies were dissolved in $\mathrm{H}_{2} \mathrm{O}$ at a concentration of $1 \mathrm{mg} / \mathrm{mL}$, and a saturated solution of $\mathrm{SA}$ in $0.1 \%$ TFA in $\mathrm{ACN}: \mathrm{H}_{2} \mathrm{O}(1: 1)$ was used as a matrix. Antibodies $(2 \mu \mathrm{L})$ were spotted onto a ground steel 384 target plate, mixed with $2 \mu \mathrm{L}$ of matrix solution, and vacuum dried. FlexControl 3.0 software was used for spectral acquisition, while using the following instrumental parameters: mass range at $\mathrm{m} / \mathrm{z} 2,000-300,000$, deflection suppressed up to $\mathrm{m} / \mathrm{z} 5,000$, shots accumulated to 1,000 replicates, laser frequency at $100 \mathrm{~Hz}$, and voltage on Ion Source I $25 \mathrm{kV}$, Ion Source II $23 \mathrm{kV}$, and Lens $9 \mathrm{kV}$.

\section{UPLC for binding site analysis}

The column temperature was set to $40^{\circ} \mathrm{C}$ and a flow rate of $0.3 \mathrm{~mL} / \mathrm{min}$ was maintained. The digested, reduced, and alkylated sample was injected into the column at a volume of $10 \mu \mathrm{L}$. Mobile phase $A$ consisted of water with $0.1 \%$ formic acid, while mobile phase $B$ consisted of acetonitrile with $0.1 \%$ formic acid. The initial gradient condition was $2 \%$ B for 5 min, then B was increased gradually to $45 \%$ in 115 $\mathrm{min}$, followed by a gradient increase from $45 \%$ B to $100 \%$ B in $5 \mathrm{~min}$. The column was then washed with $100 \%$ B for 5 min followed by equilibration at $2 \%$ B for 5 min.

The peptides for analysis were loaded via a Dionex Nano-trap column $(30 \mu \mathrm{m} \times 10 \mathrm{~cm}$, Thermo Fisher Scientific), and subsequent peptide separation was performed on an Acclaim PepMap EASY-Spray analytical column $(75 \mu \mathrm{m} \times 25 \mathrm{~cm}$, nanoViper, C18, $2 \mu \mathrm{m}, 100 \AA$, Thermo Fisher Scientific). For each liquid chromatography tandem mass spectrometry (LC-MS/MS) analysis, the peptides were loaded onto a precolumn with microliter pickup. The peptides were separated at a flow rate of $300 \mathrm{~nL} / \mathrm{min}$ using a mobile phase of acetonitrile with $0.1 \%$ formic acid in a gradient of $10-40 \%$ over $120 \mathrm{~min}$.

\section{Synthetic methods}

\subsection{Synthesis of peptides}

5-Exo-norbornene-NHS ester (I): This compound was synthesized using a previously reported procedure ${ }^{1}$ and obtained as white solid. $\mathrm{R}_{\mathrm{f}}=0.3$ (33\% EtOAc in Hex); MS (ESI): m/z $235.29[\mathrm{M}+\mathrm{H}]^{+}$

Photoreactive FcBP (pFcBP): (sequence: Norbornene-PEG8-DCAWHpLGELVWCT, Figure S1) This was synthesized by solid-phase peptide synthesis (SPPS) using Fmoc-protected amino acids. $\mathrm{PEG}_{8}$ was attached to the $N$-terminus of the peptide. The synthesized peptide was cleaved under strongly acidic conditions (TFA:TIS:EDT: $\mathrm{H}_{2} \mathrm{O}=94: 1: 2.5: 2.5$ ). The crude peptide was obtained via ether precipitation and collected by centrifugation. The disulfide bond was formed under mild oxidation

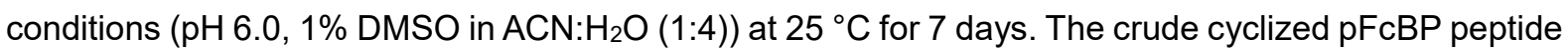
was purified by reverse phase chromatography. Finally, norbornene was attached to the $N$-terminus of the peptide using 5-exo-norbornene-NHS ester (compound I) and 6 equivalents (equiv.) of DIPEA in DMF. The final pFcBP was purified by preparative HPLC and obtained as white solid by lyophilizing; the purity was verified by analytical HPLC. MS (ESI): m/z $2086.7[\mathrm{M}+\mathrm{H}]^{+}, 2106.2[\mathrm{M}+\mathrm{Na}]^{+}, 1042.2[\mathrm{M}+2 \mathrm{H}]^{2+}$ 
FcBP-biotin (bFcBP): (sequence: Biotin-PEG ${ }_{8}-D C A W H K G E L V W C T$, Figure S2) This was also synthesized using SPPS. Biotin-NHS ester and DIPEA were reacted to couple with the peptide on resin. After attaching biotin, cleavage of the synthesized peptide and subsequent formation of a disulfide bond were performed using the same conditions as those for $\mathrm{pFcBP}$, as described above. The crude cyclized bFcBP peptide was purified by reverse phase chromatography. The functional group disuccinimidyl glutarate (DSG) was attached to the Lys residue to enable covalent linkage with trastuzumab. The final bFcBP was purified by preparative HPLC and obtained as white solid by lyophilizing; the purity was verified by analytical HPLC. MS (ESI): m/z $1203.5[\mathrm{M}+2 \mathrm{H}]^{2+}$

pFcBP- $\mathrm{NH}_{2}$ : The $\mathrm{N}$-terminal amine-functionalized pFcBP peptide (sequence: $\mathrm{H}_{2} \mathrm{~N}-\mathrm{PEG}_{8}$ DCAWHpLGELVWCT, Figure S3) was also synthesized using SPPS. The cleavage of the synthesized peptide and subsequent formation of a disulfide bond were performed under the same conditions as those used for $\mathrm{pFcBP}$, as described above. The crude cyclized $\mathrm{pFcBP}-\mathrm{NH}_{2}$ peptide was purified by preparative HPLC and obtained as white solid by lyophilizing; its purity was verified by analytical HPLC. MS (ESI): m/z 1966.6 [M+H] $]^{+}, 983.6[\mathrm{M}+2 \mathrm{H}]^{2+}$

FcBP- $\mathrm{NH}_{2}$ : The $\mathrm{N}$-terminal amine-functionalized $\mathrm{FcBP}$ peptide (sequence: $\mathrm{H}_{2} \mathrm{~N}-\mathrm{PEG}_{8}-$ DCAWHLGELVWCT, Figure S4) was also synthesized using SPPS. The cleavage of the synthesized peptide and subsequent formation of a disulfide bond were performed using the same conditions as those used for pFcBP, as described above. The crude cyclized $\mathrm{FcBP}-\mathrm{NH}_{2}$ peptide was purified by preparative HPLC and obtained as white solid by lyophilizing; its purity was verified by analytical HPLC. MS (ESI): m/z $1955.4[\mathrm{M}+\mathrm{H}]^{+}, 977.7[\mathrm{M}+2 \mathrm{H}]^{2+}$

\subsection{Synthesis of 4-methyltetrazine-PEG ${ }_{8}-S M C C-D M 1$}

4-methyltetrazine-PEG ${ }_{8}-F_{m o c}(1)$ : HATU (380 mg, $\left.1.0 \mathrm{mmol}\right)$ and DIPEA (0.3 mL, $1.7 \mathrm{mmol}$ ) were added slowly to a solution of Fmoc-PEG ${ }_{8}-\mathrm{OH}(530 \mathrm{mg}, 0.8 \mathrm{mmol})$ in $7 \mathrm{~mL}$ DMF. The mixture was stirred for $10 \mathrm{~min}$ before adding 4-methyltetrazine- $\mathrm{NH}_{2}$ hydrochloride $(0.205 \mathrm{~g}, 0.86 \mathrm{mmol})$. The mixture was then stirred for $4 \mathrm{~h}$ at $25{ }^{\circ} \mathrm{C}$ and after completion of the reaction, the mixture was diluted with ethyl acetate. The organic layer was washed with $10 \%$ citric acid and brine. Finally, the organic layer was dried over anhydrous $\mathrm{Na}_{2} \mathrm{SO}_{4}$, then filtered, and the solvent was removed under reduced pressure. The crude mixture was purified by flash chromatography (2\% MeOH in DCM) to yield compound 1 (500 mg, $74 \%)$ as a pink oil. $\mathrm{R}_{\mathrm{f}}=0.3\left(5 \% \mathrm{MeOH}\right.$ in DCM); $\mathrm{MS}(\mathrm{ESI}): \mathrm{m} / \mathrm{z} 847.52[\mathrm{M}+\mathrm{H}]^{+} ; \mathrm{HRMS}: \mathrm{m} / \mathrm{z}[\mathrm{M}+\mathrm{H}]^{+}$ Calcd. for $\mathrm{C}_{44} \mathrm{H}_{59} \mathrm{~N}_{6} \mathrm{O}_{11} 847.4237$ Found 847.4236 
4-methyltetrazine-PEG ${ }_{8}$-amine (2): In a round-bottom flask, compound 1 (500 $\mathrm{mg}, 0.6 \mathrm{mmol}$ ) was dissolved in $6 \mathrm{~mL}$ DMF and then diethylamine $(0.3 \mathrm{~mL})$ was added slowly at room temperature. The mixture was stirred for $2.5 \mathrm{~h}$. The solvent was removed under reduced pressure and further concentrated with toluene 3 times. Crude compound 2 was purified by flash chromatography (DCM:MeOH: $\left.\mathrm{NH}_{4} \mathrm{OH}=74: 23: 3\right)(326 \mathrm{mg}, 87 \%)$ as a pink oil. $\mathrm{R}_{\mathrm{f}}=0.1$ (DCM:MeOH: $\left.\mathrm{NH}_{4} \mathrm{OH}=74: 23: 3\right)$; MS (ESI): m/z 625.48 [M+H] ; HRMS: [M+H] ${ }^{+}$Calcd. for $\mathrm{C}_{29} \mathrm{H}_{49} \mathrm{~N}_{6} \mathrm{O}_{9} 625.3556$ Found 625.3555

4-methyltetrazine-PEG ${ }_{8}-S M C C-D M 1$ (II): DM1-SMCC (171 $\mathrm{mg}, 0.16 \mathrm{mmol}$ ) was added to a solution of compound $2(100 \mathrm{mg}, 0.16 \mathrm{mmol})$ in $5 \mathrm{~mL}$ of DMF followed by DIPEA ( $0.03 \mathrm{~mL}, 0.16 \mathrm{mmol}$ ). The mixture was stirred for $2 \mathrm{~h}$, and the solvent was removed under reduced pressure. Compound II was purified by flash chromatography $\left(5 \% \mathrm{MeOH}\right.$ in DCM) as a pink oil $(235 \mathrm{mg}, 93 \%)$. $\mathrm{R}_{\mathrm{f}}=0.5(10 \%$ $\mathrm{MeOH}$ in DCM); MS (ESI): m/z 1584.17 [M+H] ; $\mathrm{HRMS}:[\mathrm{M}+\mathrm{H}]^{+}$Calcd. for $\mathrm{C}_{76} \mathrm{H}_{110} \mathrm{CIN}_{10} \mathrm{O}_{22} \mathrm{~S} 1581.7200$ Found 1581.7192

\subsection{Optimization of photo-crosslinking}

The optimization of the photo-crosslinking reaction was performed using 1.25, 2.5, and 5.0 equiv. of pFcBP, respectively. A mixture of trastuzumab and pFcBP was irradiated with $365 \mathrm{~nm}$ UV light for 20 min at $4{ }^{\circ} \mathrm{C}$. Additional pFcBP was added after one irradiation and photo-crosslinking was monitored by HIC-HPLC (Figures S8, S9, and S10 and Tables S3, S4, and S5).

Photo-crosslinking of pFcBP with trastuzumab: A mixture of 1.25 equiv. pFcBP and trastuzumab $(120 \mathrm{mg})$ was incubated for $10 \mathrm{~min}$ at $25^{\circ} \mathrm{C}$ in $20 \mathrm{mM}$ of histidine-acetate buffer at pH 5.5. The mixture was subjected to photo-crosslinking at $4{ }^{\circ} \mathrm{C}$ and $365 \mathrm{~nm}$ in an UV-Crosslinker. After $20 \mathrm{~min}$, an additional 1.25 equiv. of pFcBP was added, and the mixture was again irradiated with $365 \mathrm{~nm} \mathrm{UV}$ light. After two irradiations, the unreacted $\mathrm{pFcBP}$ was removed via size exclusion chromatography (SEC) using a spin desalting column (Zeba ${ }^{\mathrm{TM}}$ spin desalting columns, $40 \mathrm{~K} \mathrm{MWCO}, 10 \mathrm{~mL}$ ). The partially purified antibody mixture was twice more reacted with 1.25 equiv. pFcBP and subjected to two irradiations. The unreacted $\mathrm{pFcBP}$ was again removed via SEC. These procedures were repeated twice more (total 10.0 equiv. of pFcBP was used). After the final photo-crosslinking (Figure S11e), the $\mathrm{pFcBP} /$ trastuzumab product was obtained as a mixture of PAR $2(70 \%)$ and PAR $1(30 \%)$ conjugate (96 $\mathrm{mg}$, recovery yield of the antibody $=80 \%$ ). All photo-crosslinking steps were monitored via HICHPLC (Figure S11). 


\subsection{Purification of antibody-peptide conjugate with PAR 2}

The $\mathrm{pFcBP} /$ trastuzumab PAR 2 conjugate was prepared by dialysis using $1 \times \mathrm{PBS}$ buffer at a $\mathrm{pH}$ of 7.4. The mixture of $\mathrm{pFcBP} /$ trastuzumab conjugate (PAR 1 and PAR 2) was treated with $b F c B P$ to remove $P A R$ 1. Four equivalents of $b F c B P$ were used with respect to the PAR 1 conjugate. The reaction of PAR 1 with bFcBP was removed via streptavidin bead pull-down. After biotin-streptavidin pull-down, a highly pure PAR 2 conjugate was obtained. The removal of PAR 1 was monitored via HIC-HPLC (Figure S12), and the intact mass of PAR 2 was obtained via MALDI-TOF analysis (Figure S13).

\subsection{Production of homogeneous ADC}

To produce homogenous ADCs with a bio-orthogonal handle, the buffer system of the pFcBP/trastuzumab PAR 2 conjugate was modified to a slightly acidic condition (20 mM histidineacetate, $\mathrm{pH}$ 5.5). For conjugation of the payload using a bio-orthogonal handle, 4 equiv. of payload (Compound II) with respect to trastuzumab was reacted with PAR 2. The mixture was incubated for 1 day at room temperature. The payload conjugation was monitored via HIC-HPLC. To obtain the ADC of DAR 2, spin desalting and dialysis were performed to remove the unreacted payload. The intact mass of the ADC with DAR 2 was obtained via MALDI-TOF analysis (Figure S14).

\section{Surface plasmon resonance assay}

The FcBP-NH 2 and pFcBP-NH $\mathrm{N}_{2}$ peptides were coupled to the surface of a CM- 5 sensor chip by standard amine-coupling chemistry on the SPR instrument. Briefly, a mixture of EDC (0.4 M) and NHS (0.1 M) was injected onto the chip to activate carboxyl groups on the sensor surface. Subsequently, $100 \mu \mathrm{g} / \mathrm{mL}$ of FcBP-NH $\mathrm{N}_{2}$ and $\mathrm{pFcBP}-\mathrm{NH}_{2}$ were added at the same flow rate. Excess reactive groups were blocked with $1 \mathrm{M}$ ethanolamine $(\mathrm{pH} 8.5)$. Varying concentrations of trastuzumab $(0.39,0.78,1.56,3.13,6.25$, $12.5,25$, and $50 \mathrm{nM}$ ) were prepared in $\mathrm{pH} 7.4$ TBS-T and injected at a flow rate of $30 \mu \mathrm{L} / \mathrm{min}$. The chip surface was regenerated using a $20 \mathrm{mM} \mathrm{NaOH}$ solution. The binding constants were derived by globally fitting the SPR data to a Langmuir (1:1) model using BIAevaluation software provided by the manufacturer. 


\section{Binding site analysis}

Enzymatic digestion: First, $20 \mu \mathrm{g}(5 \mathrm{mg} / \mathrm{mL})$ of the antibodies were prepared and diluted to $16 \mu \mathrm{L}$ with denaturing buffer comprising $6 \mathrm{M}$ urea in $50 \mathrm{mM}$ Tris- $\mathrm{HCl}$ at $\mathrm{pH}$ 7.5. The disulfide bond reduction of the antibodies was achieved by the addition of $1 \mu \mathrm{L}$ of $200 \mathrm{mM}$ dithiothreitol (DTT) in $50 \mathrm{mM}$ Tris$\mathrm{HCl}$, followed by incubation at $37^{\circ} \mathrm{C}$ for $1 \mathrm{~h}$. The alkylation of the generated thiol was performed by adding $4 \mu \mathrm{L}$ of $200 \mathrm{mM}$ iodoacetamide (IAA) in $50 \mathrm{mM}$ Tris- $\mathrm{HCl}$ at room temperature for $30 \mathrm{~min}$ in the dark. For enzymatic digestion, trypsin $(1: 50, \mathrm{w} / \mathrm{w})$ was added to the protein solution and incubated at $37^{\circ} \mathrm{C}$ for $16 \mathrm{~h}$. When the digestion was complete, $1 \mu \mathrm{L}$ of formic acid was added. The digested sample was stored at $4{ }^{\circ} \mathrm{C}$ until analysis.

Data analysis: The resulting MS/MS data were searched against the trastuzumab sequence using Proteome Discoverer 2.3 (Thermo Fischer Scientific) and BioPharma Finder 3.1 (Thermo Fischer Scientific). For the Proteome Discoverer search, Sequest HT was used as a search engine and the total intensity threshold was set to $0.01 \%$ intensity of the peak top of the base peak chromatogram. The minimum peptide length was set to 4 amino acids and the maximum peptide length was set to 150 amino acids.

The mass tolerance of precursor ions and fragment ions were set to $10 \mathrm{ppm}$ and $0.6 \mathrm{Da}$, respectively. The alkylation of cysteine $(+57.021 \mathrm{Da})$ was specified as a fixed modification, and oxidation of methionine $(+15.995 \mathrm{Da})$ was included as a variable modification. Fragments without high peptide confidence were filtered out. To search for BioPharma Finder 3.1, the threshold of signal-to-noise was set to 20 , and MS noise level was defined by MS signal threshold to be $1 \%$ intensity of the peak top of the base peak chromatogram. Two missed cleavages were allowed for fully tryptic peptides. The maximum peptide mass was set at $\mathrm{m} / \mathrm{z} 15,000$ and the mass tolerance was set to $4 \mathrm{ppm}$. Fixed modifications and variable modifications were set similarly to search Proteome Discoverer 2.3. Fragments with a confidence score higher than $80 \%$ and with MS2 spectrum were counted for analysis (Figures S15-18).

\section{Antigen binding assay}

HER2/v (10004-H08H100, Sinobio) was coated in an ELISA plate (100 ng per well) and incubated at $4{ }^{\circ} \mathrm{C}$ for $24 \mathrm{~h}$. The plate was washed three times with TBS-T. BSA (3\%) was incubated for $1.5 \mathrm{~h}$ at room temperature. After blocking, the buffer was discarded, and serially diluted samples were added and incubated for $1.5 \mathrm{~h}$ at room temperature. The plate was washed three times with $100 \mu \mathrm{L}$ of TBS-T. Then, each well was incubated with $F\left(a b^{\prime}\right)$ 2-Goat anti-human IgG $(H+L)$ conjugated HRP (PA5-33290, Thermo Fisher Scientific) at room temperature for $1.5 \mathrm{~h}$. The plate was washed, then was incubated with TMB solution (T0440, Sigma) for $3 \mathrm{~min}$ and $0.5 \mathrm{M} \mathrm{H}_{2} \mathrm{SO}_{4}$ (stop solution) was added. A wavelength of $450 \mathrm{~nm}$ was used for measuring the absorbance using a plate reader (Multiskan GO, Thermo Scientific). 


\section{Cell viability assay}

Cancer cells were seeded in a 96-well optical-bottom plate $(5,000$ cells per well, 165306 , Thermo Fisher Scientific) and incubated at $37{ }^{\circ} \mathrm{C}$ under $5 \% \mathrm{CO}_{2}$ for $24 \mathrm{~h}$. After the media was discarded, serially diluted antibodies were added and incubated at $37^{\circ} \mathrm{C}$ for $120 \mathrm{~h}$ (NCI-N87) or $96 \mathrm{~h}$ (MDA-MB-231). Cell viability was assessed by CellTiter-Glo (G7570, Promega).

\section{References.}

1. Werther, P.; Möhler, J. S.; Wombacher, R., A Bifunctional Fluorogenic Rhodamine Probe for Proximity-Induced Bioorthogonal Chemistry. Chemistry - A European Journal 2017, 23, 18216-18224. 
Structures and HPLC chromatograms of purified FcBP derivatives and payload Photoreactive FcBP (pFcBP)

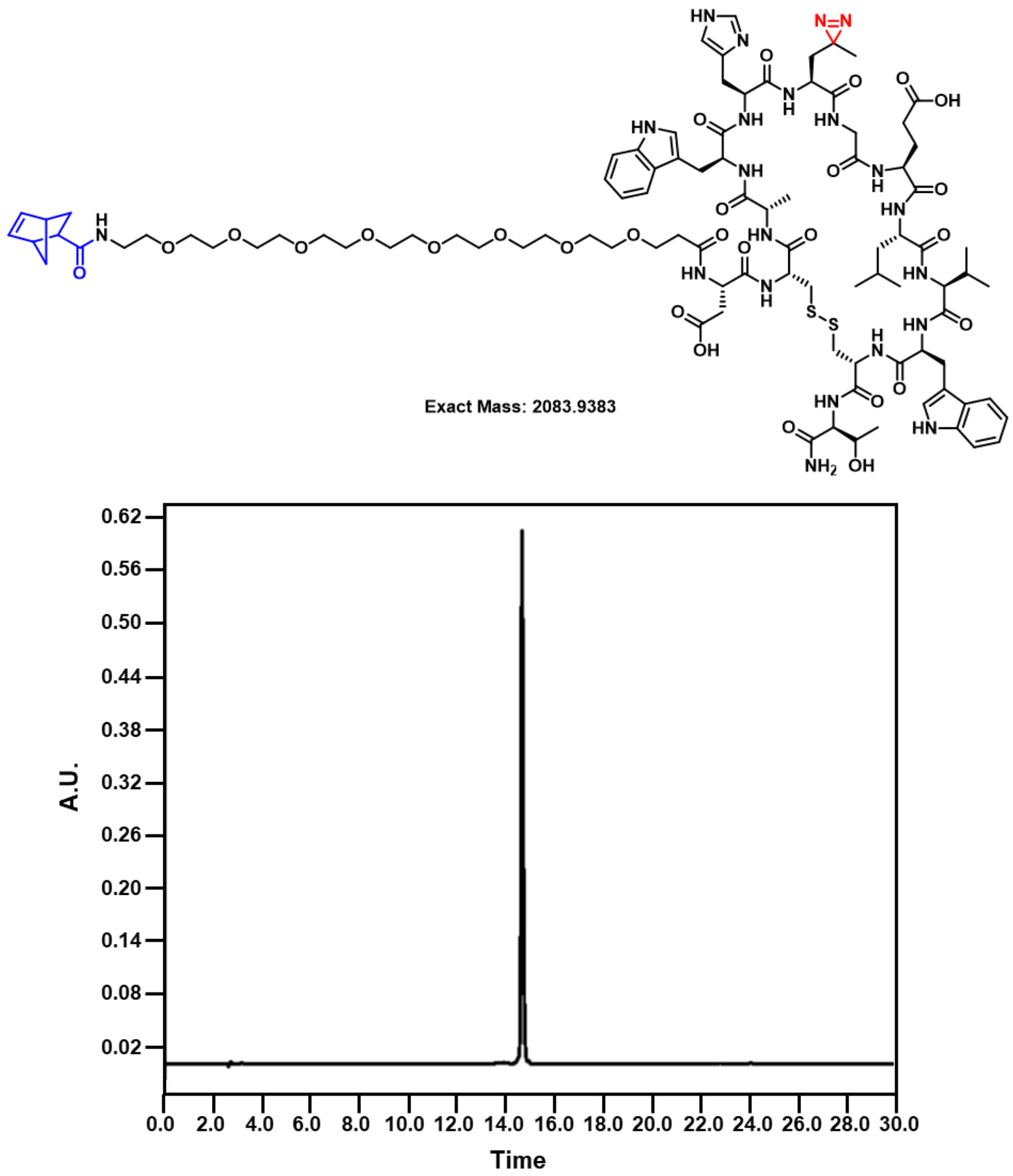

Figure S1. The chemical structure and HPLC chromatogram (RT = $14.7 \mathrm{~min}$ ) of photoreactive FcBP (pFcBP). 


\section{FcBP-biotin (bFcBP)}
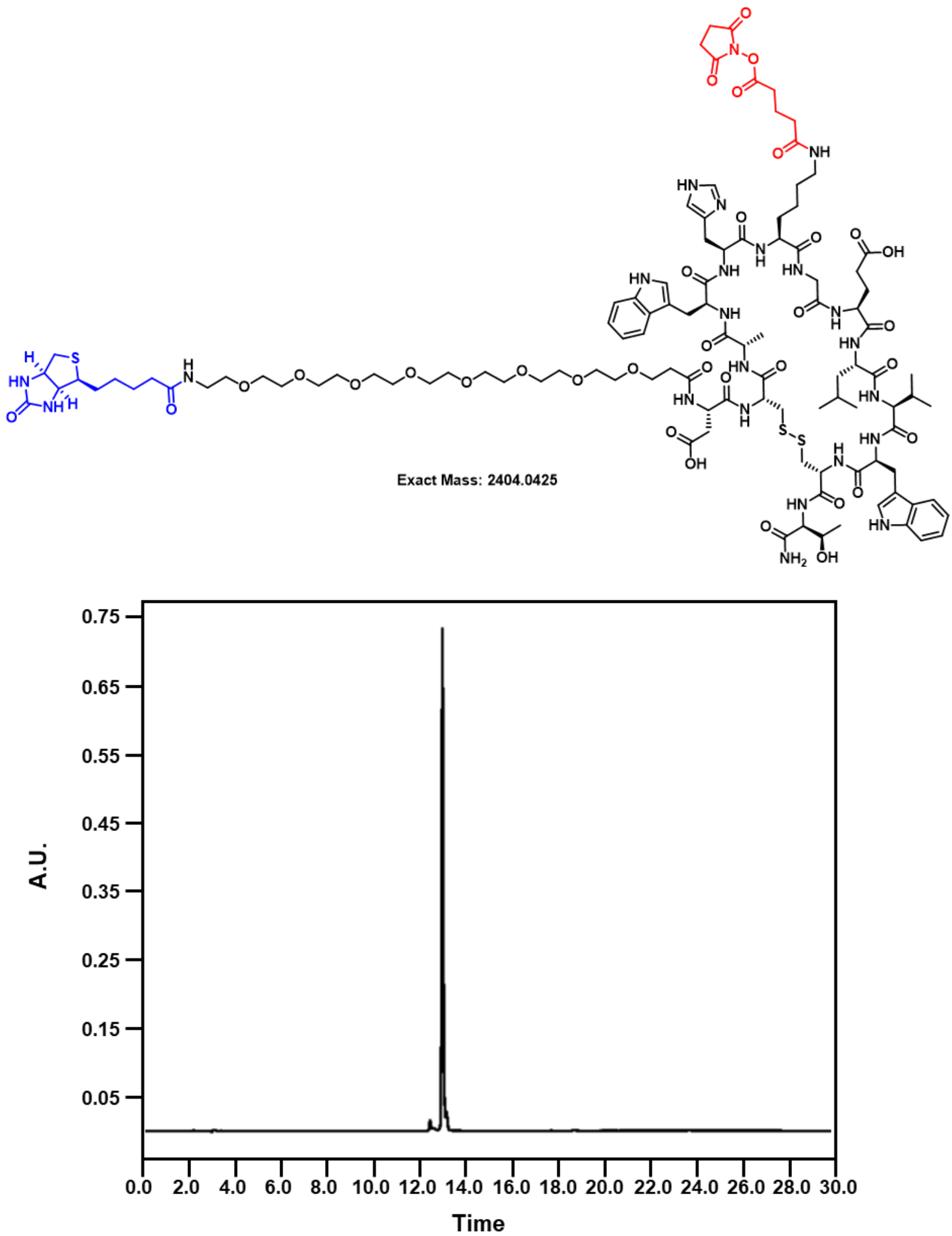

Figure S2. The chemical structure and HPLC chromatogram of $(R T=13.0 \mathrm{~min})$ FcBP-biotin (bFcBP). 

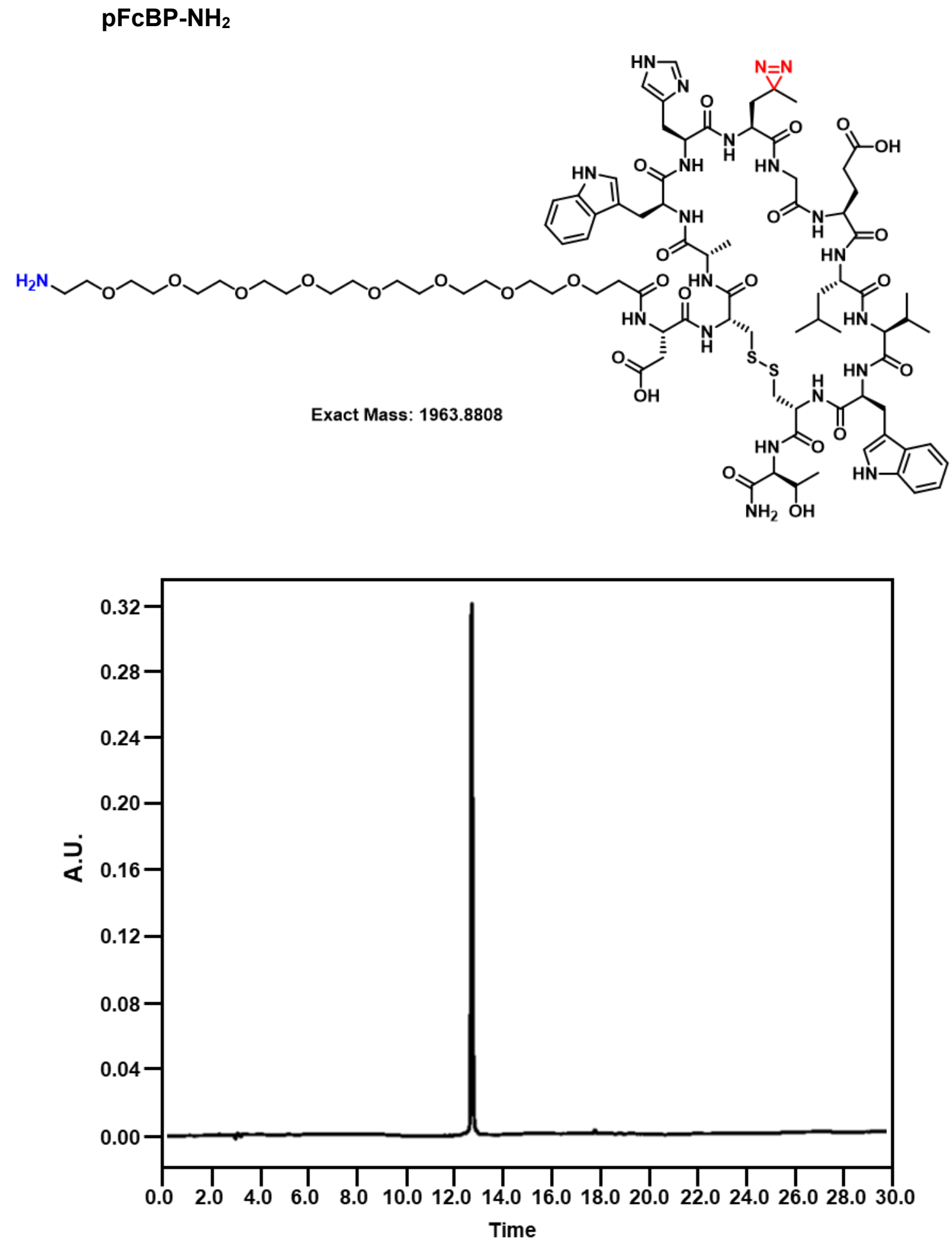

Figure S3. The chemical structure and HPLC chromatogram $(\mathrm{RT}=12.7 \mathrm{~min})$ of $\mathrm{pFcBP}-\mathrm{NH}_{2}$. 
FcBP-NH
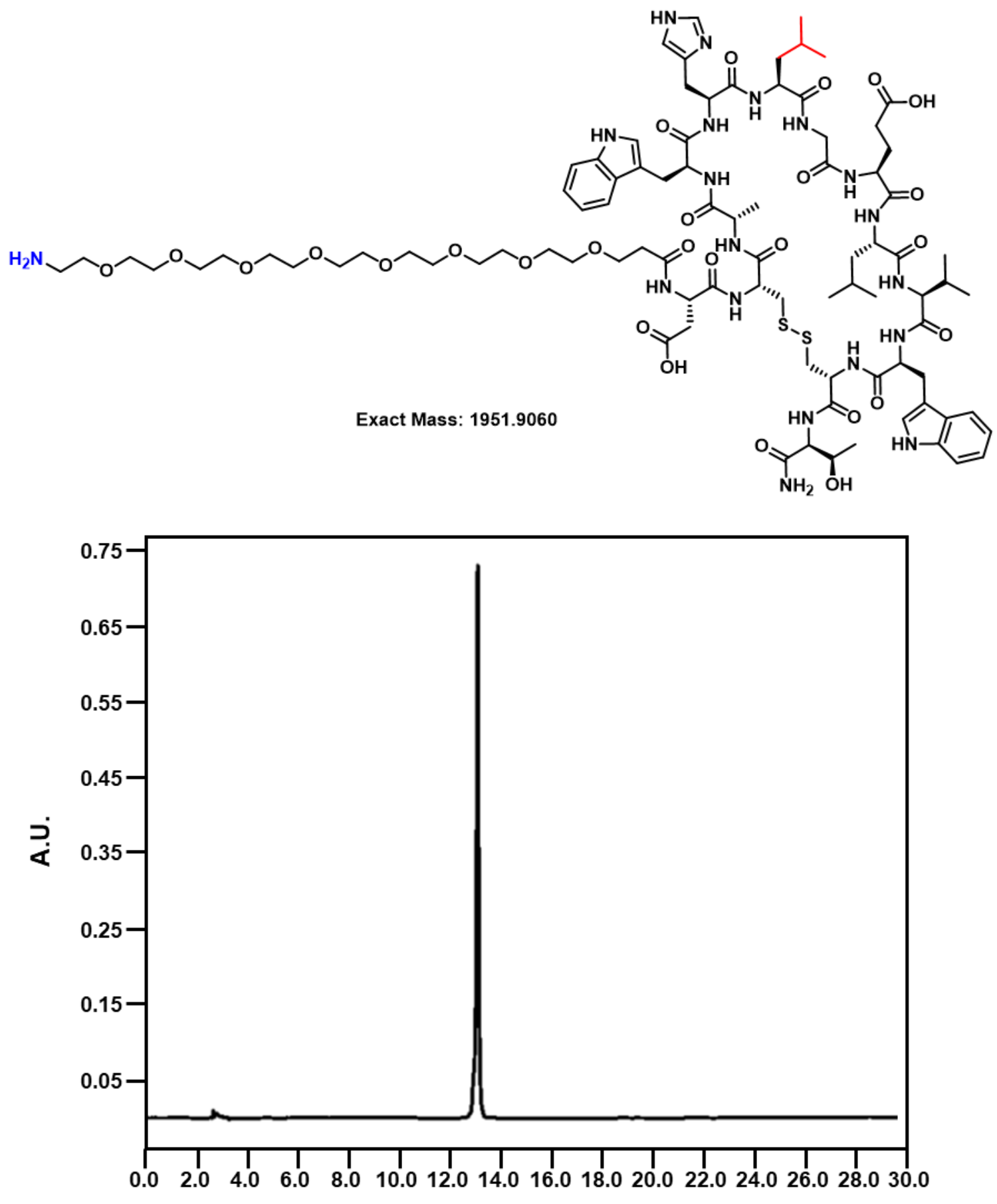

Time

Figure S4. The chemical structure and HPLC chromatogram (RT = $13.1 \mathrm{~min})$ of FcBP-NH 

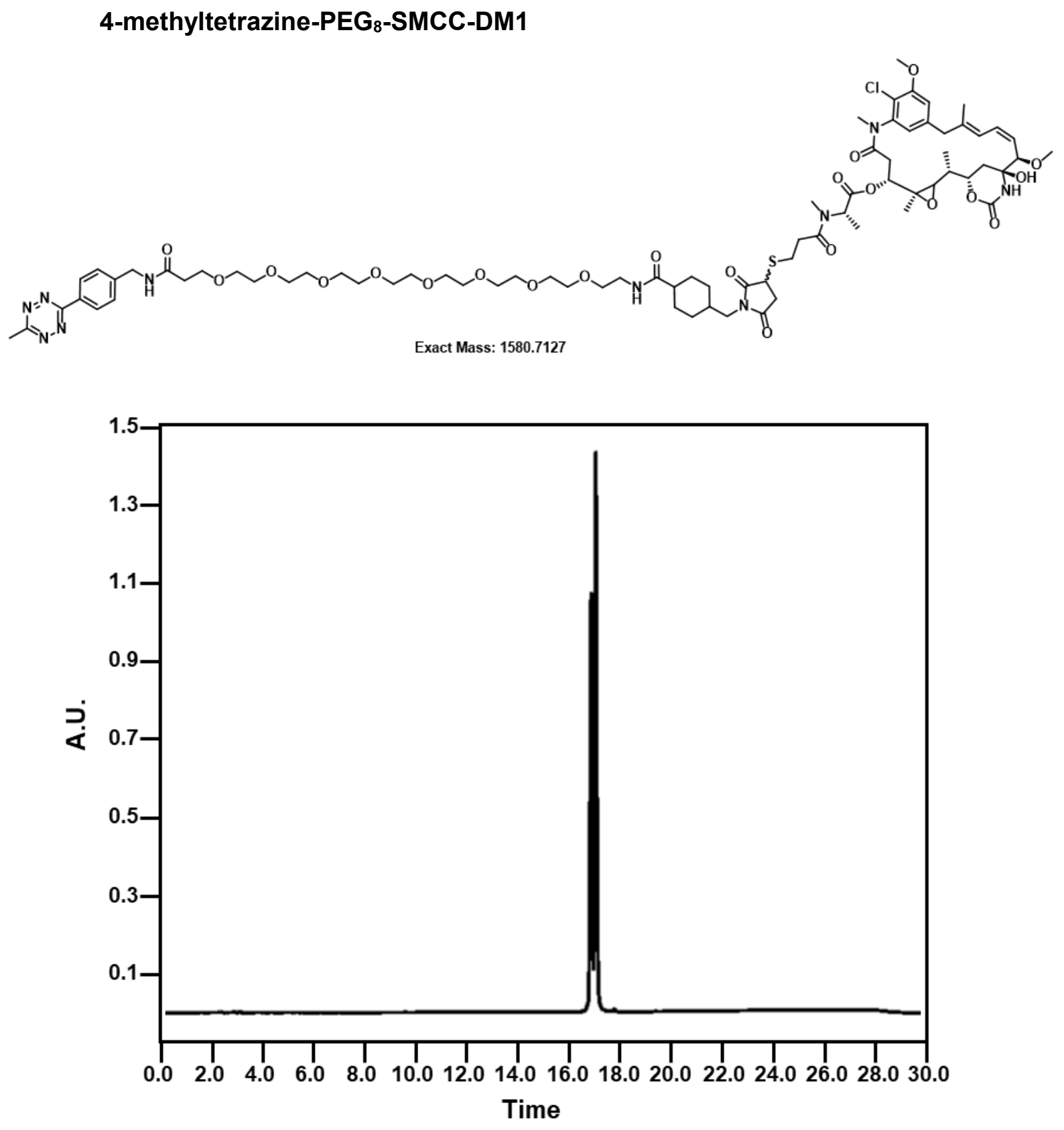

Figure S5. The chemical structure and HPLC chromatogram (RT = $17.2 \mathrm{~min})$ of 4-methyltetrazinePEG 8 -SMCC-DM1. 


\section{Surface plasmon resonance (SPR) assay}

pFcBP-NH

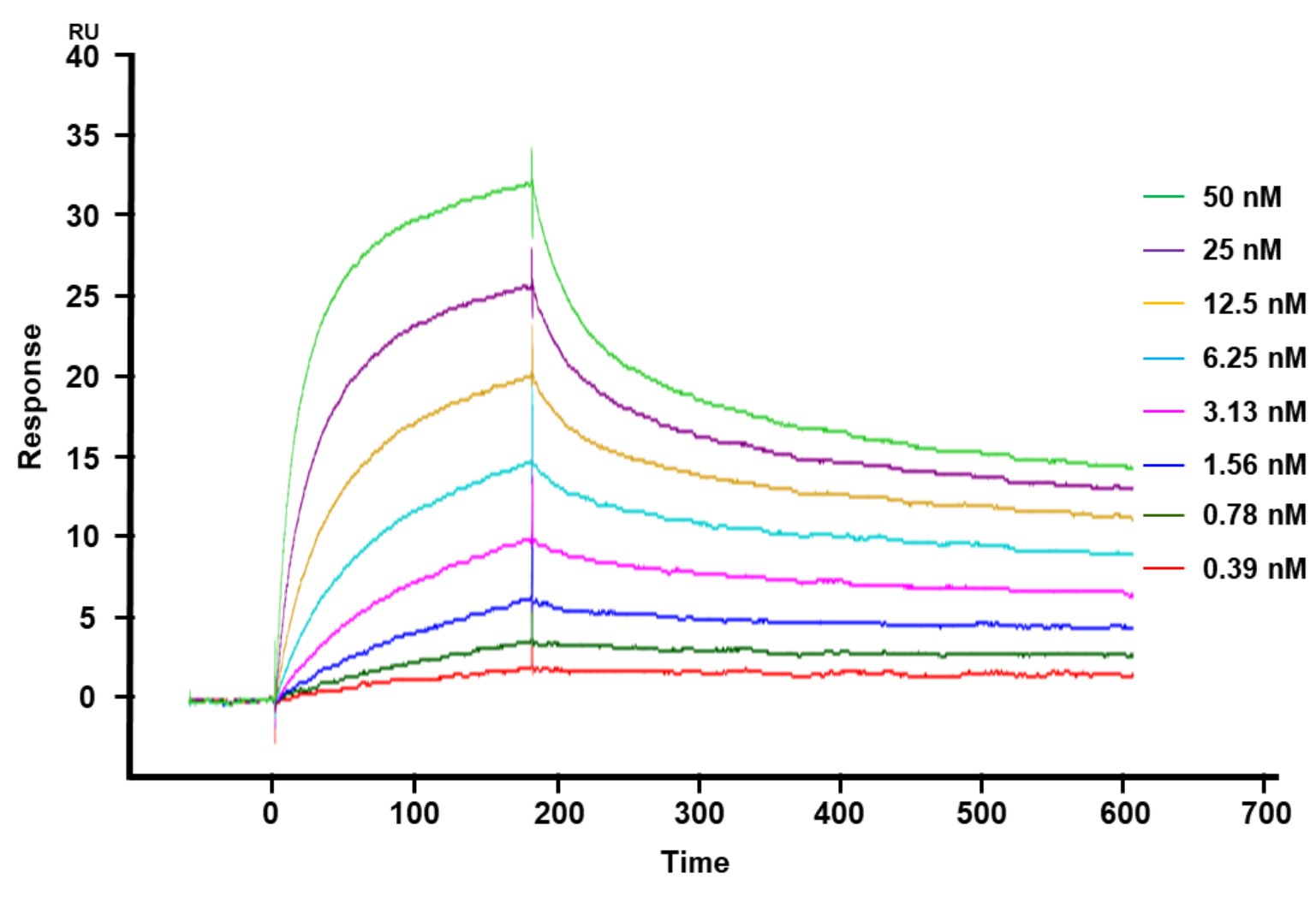

Figure S6. SPR analysis of the binding affinity between $\mathrm{pFcBP}-\mathrm{NH}_{2}$ and trastuzumab. The binding affinity of trastuzumab with $\mathrm{pFCBP}-\mathrm{NH}_{2}$, which was immobilized on a CM-5 chip, where the $\mathrm{K}_{\mathrm{D}}$ value was calculated as $1.26 \mathrm{nM}$.

Table S1. Binding constants of $\mathrm{pFcBP}-\mathrm{NH}_{2}$ as SPR values

\begin{tabular}{|c|c|c|c|c|}
\hline Concentration $(\mathrm{nM})$ & $\mathrm{K}_{\text {on }}(1 / \mathrm{Ms})$ & $\mathrm{K}_{\text {off }}(1 / \mathrm{s})$ & $\mathrm{K}_{\mathrm{D}}(\mathrm{M})$ & $\mathrm{Chi}^{2}$ \\
\hline $0.39-50$ & $1.04 \times 10^{6}$ & $1.30 \times 10^{-3}$ & $1.26 \times 10^{-9}$ & 1.08 \\
\hline
\end{tabular}




\section{FcBP-NH}

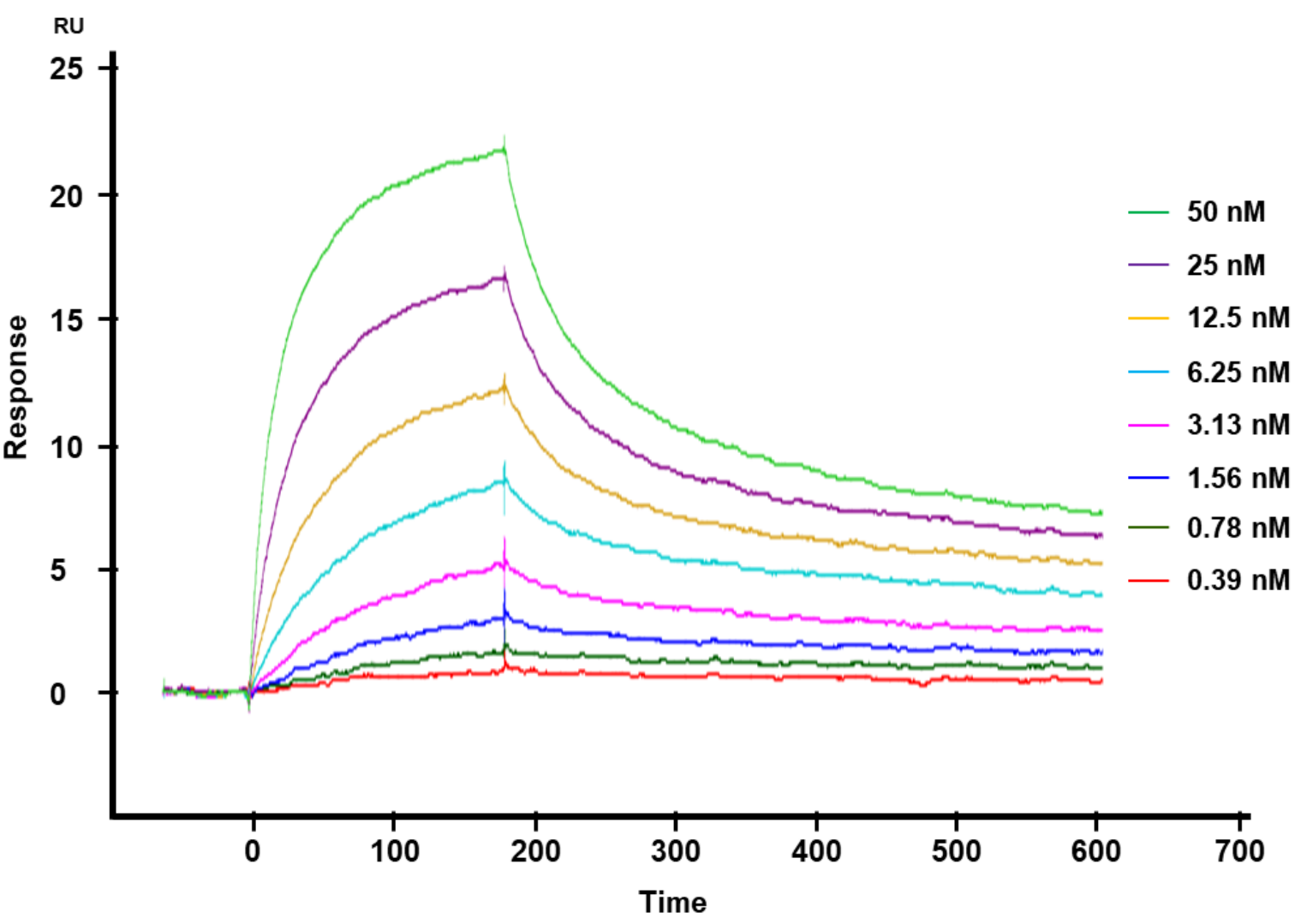

Figure S7. SPR analysis of the binding affinity between FcBP-NH $\mathrm{N}_{2}$ and trastuzumab. The binding affinity of trastuzumab with FCBP-NH$H_{2}$, which was immobilized on a CM- 5 chip, where the $K_{D}$ value was calculated as $3.13 \mathrm{nM}$.

Table S2. Binding constants of $\mathrm{FcBP}-\mathrm{NH}_{2}$ as SPR values

\begin{tabular}{|c|c|c|c|c|}
\hline Concentration $(\mathrm{nM})$ & $\mathrm{K}_{\text {on }}(1 / \mathrm{Ms})$ & $\mathrm{K}_{\text {off }}(1 / \mathrm{s})$ & $\mathrm{K}_{\mathrm{D}}(\mathrm{M})$ & $\mathrm{Chi}^{2}$ \\
\hline $0.39-50$ & $8.46 \times 10^{6}$ & $2.65 \times 10^{-3}$ & $3.13 \times 10^{-9}$ & 0.43 \\
\hline
\end{tabular}


Photo-crosslinking using 1.25 equiv. of pFcBP with trastuzumab

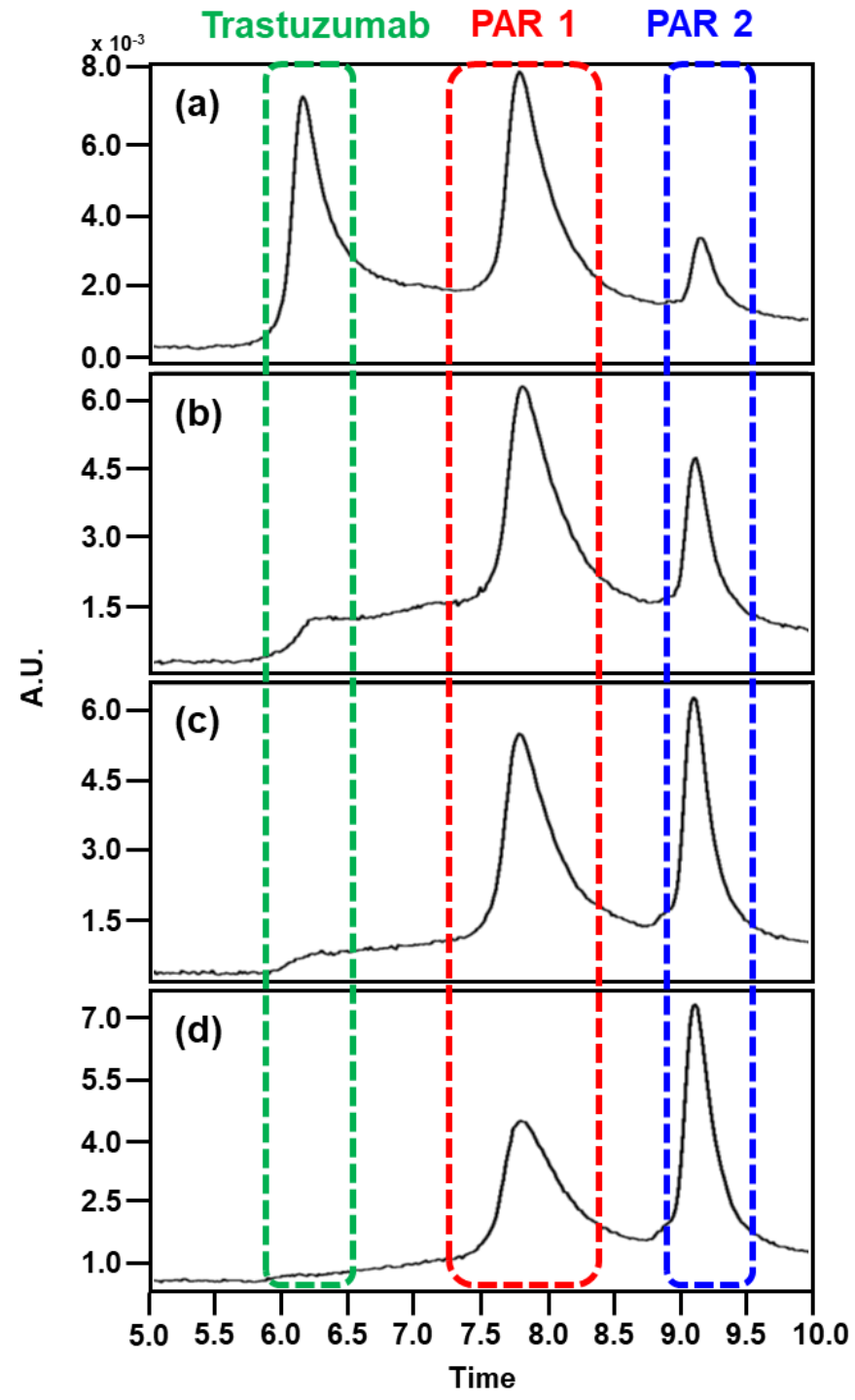

Figure S8. HIC-HPLC chromatograms of four irradiations for photo-crosslinking using 1.25 equiv. of $\mathrm{pFcBP}$ with trastuzumab. (a) One irradiation of $\mathrm{pFcBP}$ with trastuzumab $(1 \times 1.25$ equiv. $\mathrm{pFcBP})$. (b) Two irradiations of $\mathrm{pFcBP}$ with trastuzumab $(2 \times 1.25$ equiv. $\mathrm{pFcBP})$. (3) Three irradiations of $\mathrm{pFcBP}$ with trastuzumab $(3 \times 1.25$ equiv. pFcBP $)$. (d) Four irradiations of pFcBP with trastuzumab $(4 \times 1.25$ equiv. $\mathrm{pFcBP}$ ).

Table S3. PAR ratio for photo-crosslinking using 1.25 equiv. of pFcBP with trastuzumab

\begin{tabular}{|c|c|c|c|}
\hline & PAR 0 (Trastuzumab) & PAR 1 (7.7 min) & PAR 2 (9.1 min) \\
\hline $\begin{array}{c}\text { One irradiation } \\
(1 \times 1.25 \text { equiv. pFcBP) }\end{array}$ & $40 \%$ & $48 \%$ & $12 \%$ \\
\hline $\begin{array}{c}\text { Two irradiations } \\
(2 \times 1.25 \text { equiv. pFcBP })\end{array}$ & $16 \%$ & $61 \%$ & $23 \%$ \\
\hline $\begin{array}{c}\text { Three irradiations } \\
(3 \times 1.25 \text { equiv. pFcBP })\end{array}$ & $8 \%$ & $55 \%$ & $37 \%$ \\
\hline $\begin{array}{c}\text { Four irradiations } \\
(4 \times 1.25 \text { equiv. pFcBP })\end{array}$ & $0 \%$ & $54 \%$ & $46 \%$ \\
\hline
\end{tabular}


Photo-crosslinking using 2.5 equiv. of pFcBP with trastuzumab

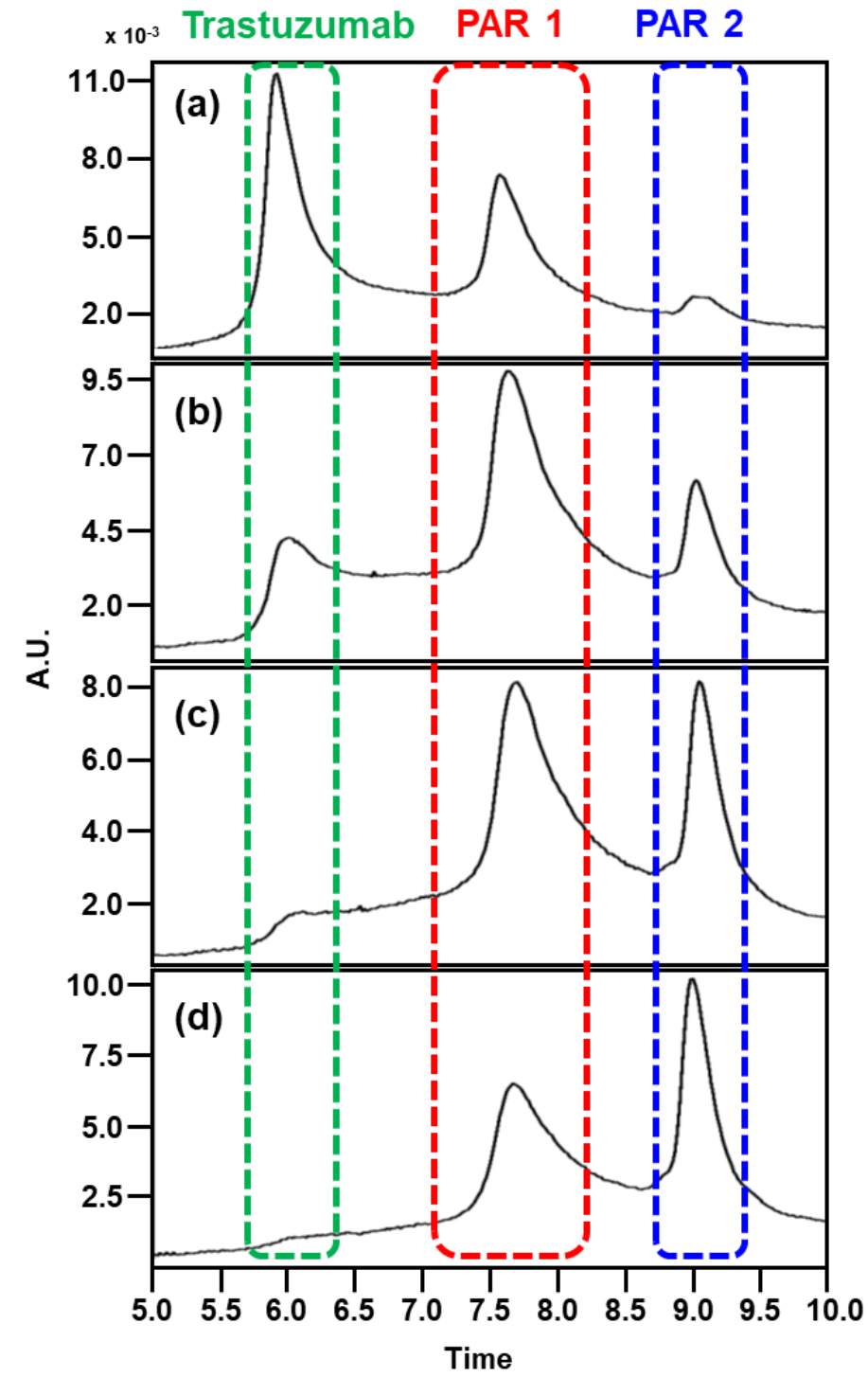

Figure S9. HIC-HPLC chromatograms of four irradiations for photo-crosslinking using 2.5 equiv. of pFcBP with trastuzumab. (a) One irradiation of pFcBP with trastuzumab $(1 \times 2.5$ equiv. pFcBP). (b) Two irradiations of $\mathrm{pFcBP}$ with trastuzumab $(2 \times 2.5$ equiv. $\mathrm{pFcBP})$. (3) Three irradiations of $\mathrm{pFcBP}$ with trastuzumab $(3 \times 2.5$ equiv. $\mathrm{pFcBP})$. (d) Four irradiations of $\mathrm{pFcBP}$ with trastuzumab $(4 \times 2.5$ equiv. pFcBP).

Table S4. PAR ratio for the photo-crosslinking using 2.5 equiv. of $\mathrm{pFcBP}$ with trastuzumab

\begin{tabular}{|c|c|c|c|}
\hline & PAR 0 (Trastuzumab) & PAR 1 (7.7 min) & PAR 2 (9.1 min) \\
\hline $\begin{array}{c}\text { One irradiation } \\
(1 \times 2.5 \text { equiv. pFcBP) }\end{array}$ & $52 \%$ & $39 \%$ & $9 \%$ \\
\hline $\begin{array}{c}\text { Two irradiations } \\
(2 \times 2.5 \text { equiv. pFcBP })\end{array}$ & $25 \%$ & $56 \%$ & $19 \%$ \\
\hline $\begin{array}{c}\text { Three irradiations } \\
(3 \times 2.5 \text { equiv. pFcBP })\end{array}$ & $9 \%$ & $59 \%$ & $32 \%$ \\
\hline $\begin{array}{c}\text { Four irradiations } \\
(4 \times 2.5 \text { equiv. pFcBP })\end{array}$ & $4 \%$ & $52 \%$ & $44 \%$ \\
\hline
\end{tabular}


Photo-crosslinking using 5.0 equiv. of pFcBP with trastuzumab

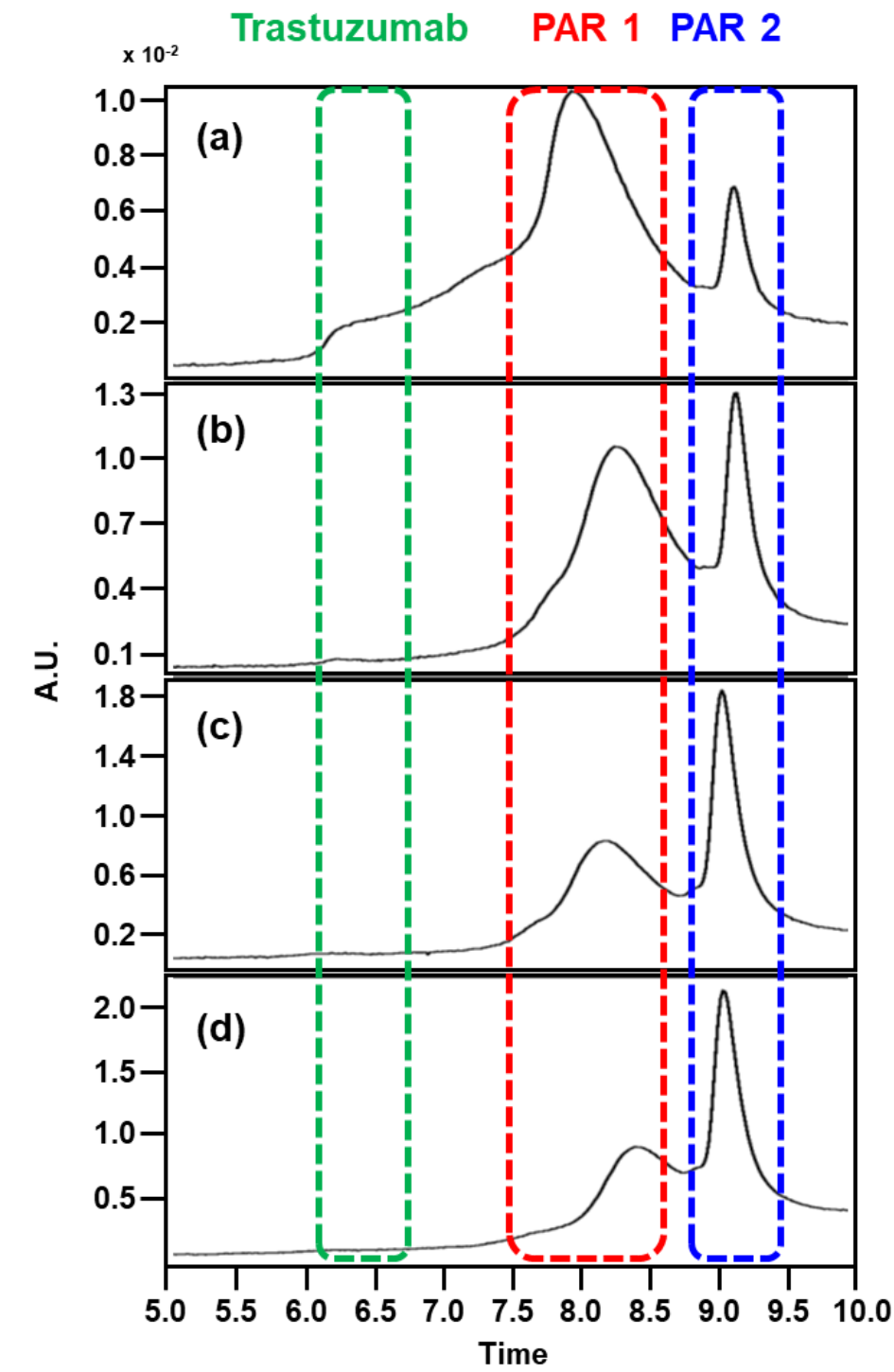

Figure S10. HIC-HPLC chromatograms of four irradiations for photo-crosslinking using 5.0 equiv. of $\mathrm{pFcBP}$ with trastuzumab. (a) One irradiation of $\mathrm{pFcBP}$ with trastuzumab $(1 \times 5.0$ equiv. pFcBP). (b) Two irradiations of $\mathrm{pFcBP}$ with trastuzumab $(2 \times 5.0$ equiv. pFcBP). (3) Three irradiations of $\mathrm{pFcBP}$ with trastuzumab $(3 \times 5.0$ equiv. $\mathrm{pFcBP})$. (d) Four irradiations of $\mathrm{pFcBP}$ with trastuzumab $(4 \times 5.0$ equiv. pFcBP).

Table S5. PAR ratio for the photo-crosslinking using 5.0 equiv. of pFcBP with trastuzumab

\begin{tabular}{|c|c|c|c|}
\hline & PAR 0 (Trastuzumab) & PAR 1 $(7.7 \mathrm{~min})$ & PAR 2 (9.1 min) \\
\hline $\begin{array}{c}\text { One irradiation } \\
(1 \times 5.0 \text { equiv. pFcBP })\end{array}$ & $11 \%$ & $75 \%$ & $14 \%$ \\
\hline $\begin{array}{c}\text { Two irradiations } \\
(2 \times 5.0 \text { equiv. pFcBP })\end{array}$ & $0 \%$ & $66 \%$ & $34 \%$ \\
\hline $\begin{array}{c}\text { Three irradiations } \\
(3 \times 5.0 \text { equiv. pFcBP })\end{array}$ & $0 \%$ & $50 \%$ & $50 \%$ \\
\hline $\begin{array}{c}\text { Four irradiations } \\
(4 \times 5.0 \text { equiv. pFcBP })\end{array}$ & $0 \%$ & $40 \%$ & $60 \%$ \\
\hline
\end{tabular}




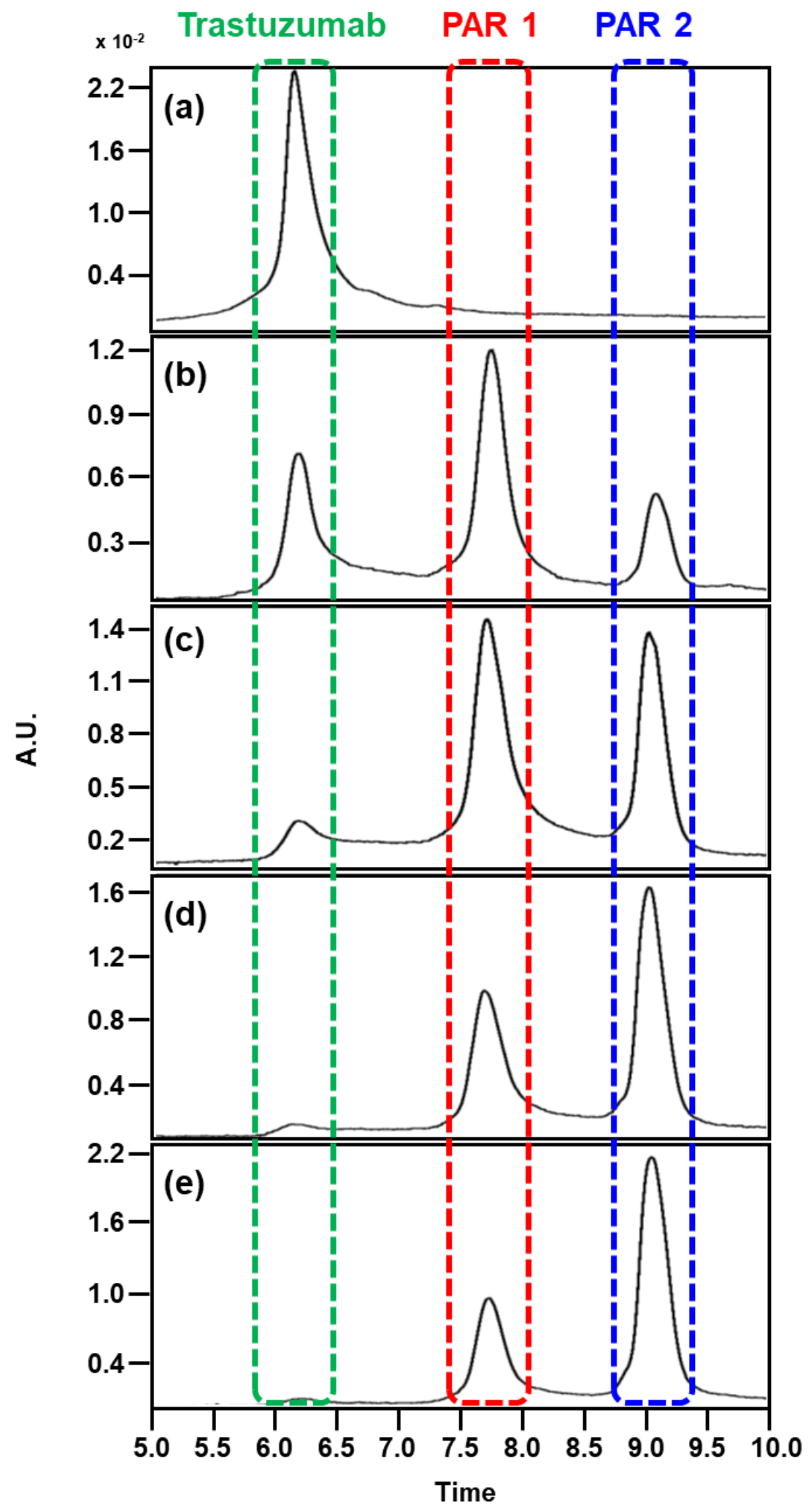

Figure S11. HIC-HPLC chromatograms for optimized photo-crosslinking of pFcBP with trastuzumab. (a) Trastuzumab. (b) Mixture after two irradiation cycles $(2 \times 1.25$ equiv. pFcBP) followed by SEC. (c) Mixture after four irradiation cycles $(4 \times 1.25$ equiv. $\mathrm{pFcBP})$ followed by SEC. (d) Mixture after six irradiation cycles $(6 \times 1.25$ equiv. pFcBP) followed by SEC. (e) Mixture after eight irradiation cycles $(8 \times 1.25$ equiv. $\mathrm{pFcBP})$ followed by SEC. 


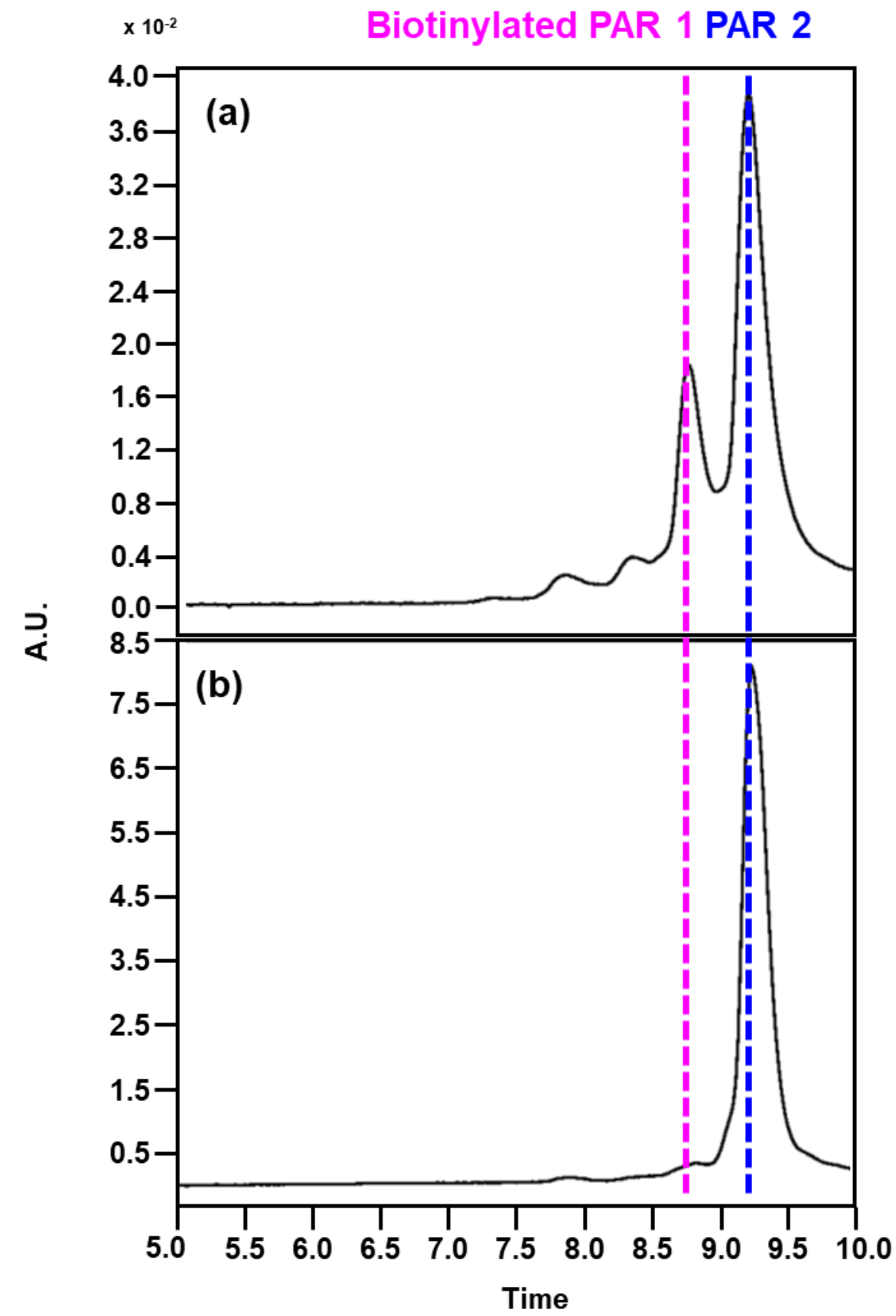

Figure S12. HIC-HPLC chromatogram after biotin-streptavidin pull-down removal of pFcBP/trastuzumab conjugate with PAR 1. (a) The crude mixture of $\mathrm{pFcBP/trastuzumab} \mathrm{conjugate}$ treated with biotin-modified FcBP. (b) Purified pFcBP/trastuzumab conjugate with PAR 2. The biotinylated antibody-peptide conjugate $(8.5 \mathrm{~min})$ was selectively removed from the reaction mixture by pull-down using streptavidin bead. 
MALDI-TOF analysis

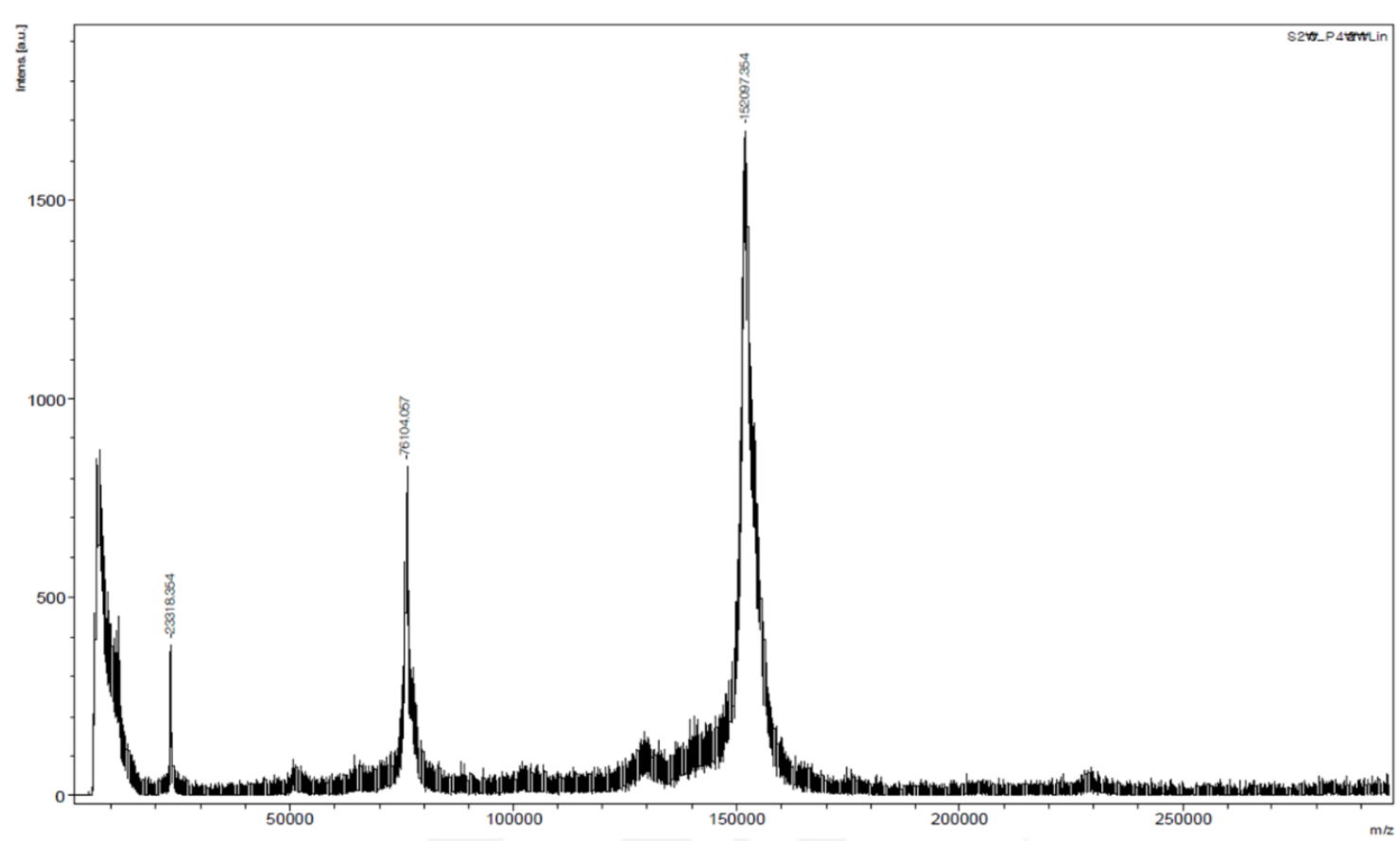

Figure S13. Molecular weight of purified PAR 2.

Expected Mass: 148,000 (Trastuzumab) $+2 \times 2,057.95\left(\mathrm{pFcBP},-\mathrm{N}_{2}\right)=152,116 \mathrm{Da}$

Obtained Mass: 152,097 Da

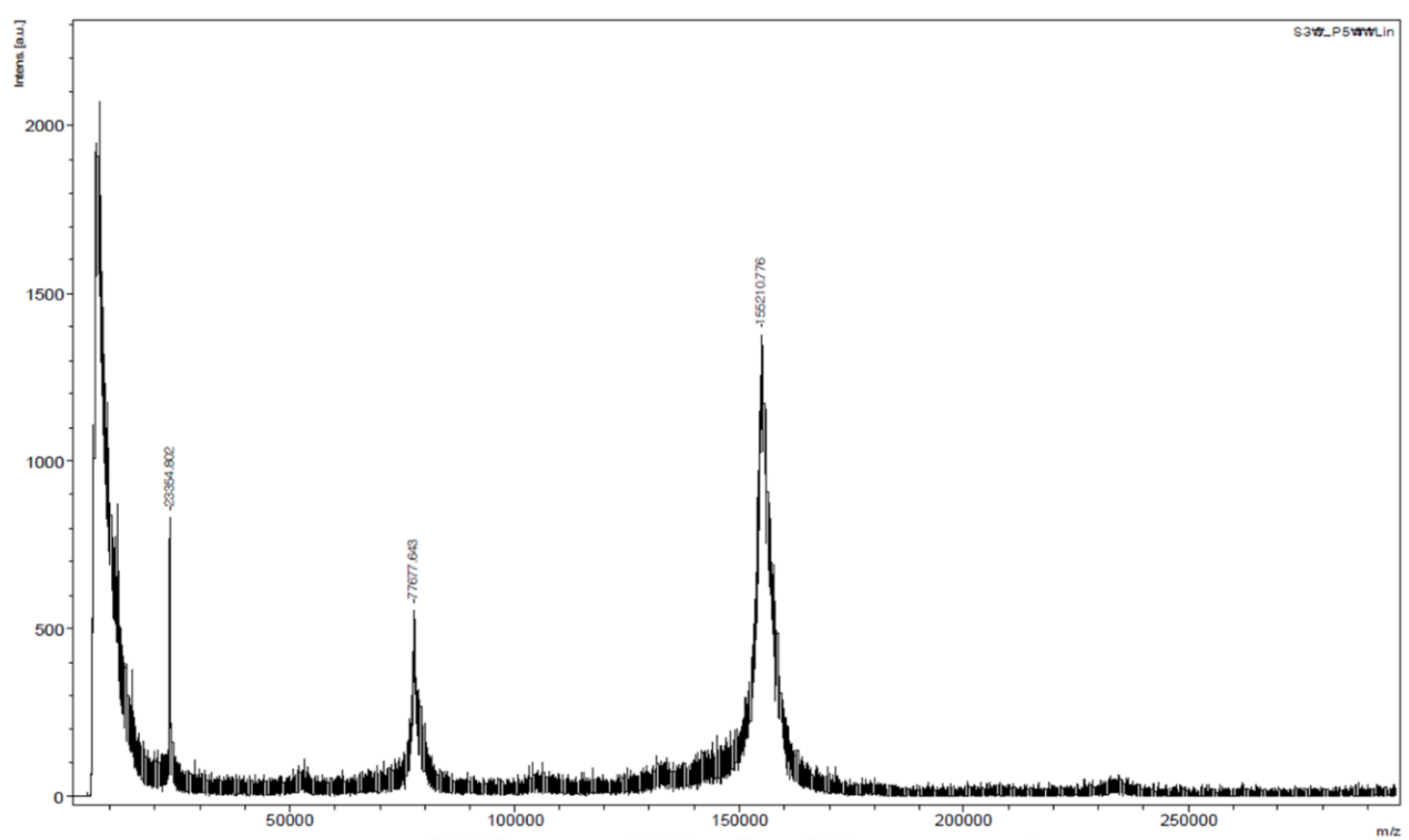

Figure S14. Molecular weight of ADC with DAR 2.

Expected Mass: $148,000($ Trastuzumab $)+2 \times 2,057.95\left(\mathrm{pFcBP},-\mathrm{N}_{2}\right)+2 \times 1580.71($ compound II $)=$ $155,278 \mathrm{Da}$

Obtained Mass: 155,210 Da 


\section{Binding Site Analysis}

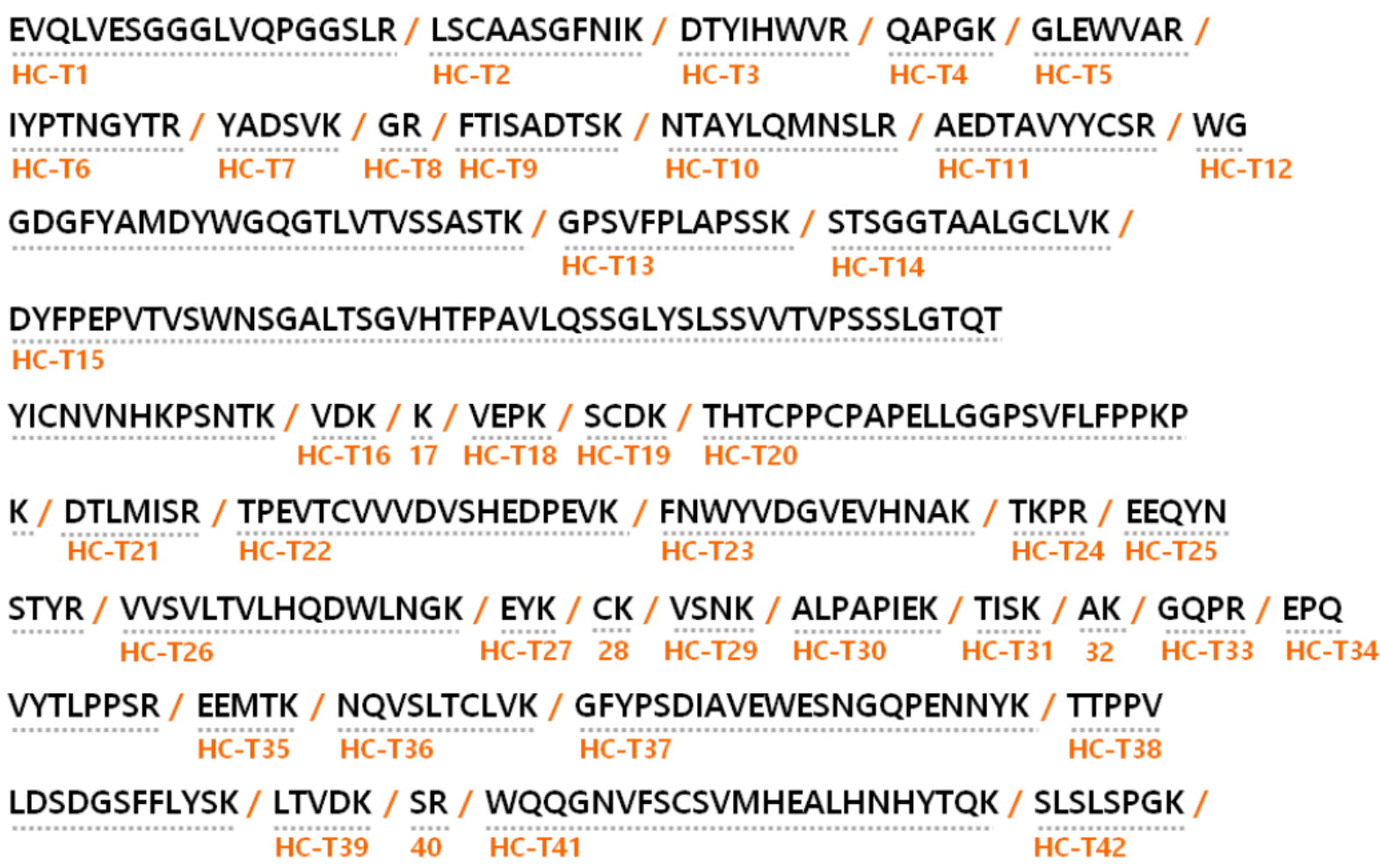

Figure S15. All heavy chain fragments of trastuzumab by trypsin digestion.

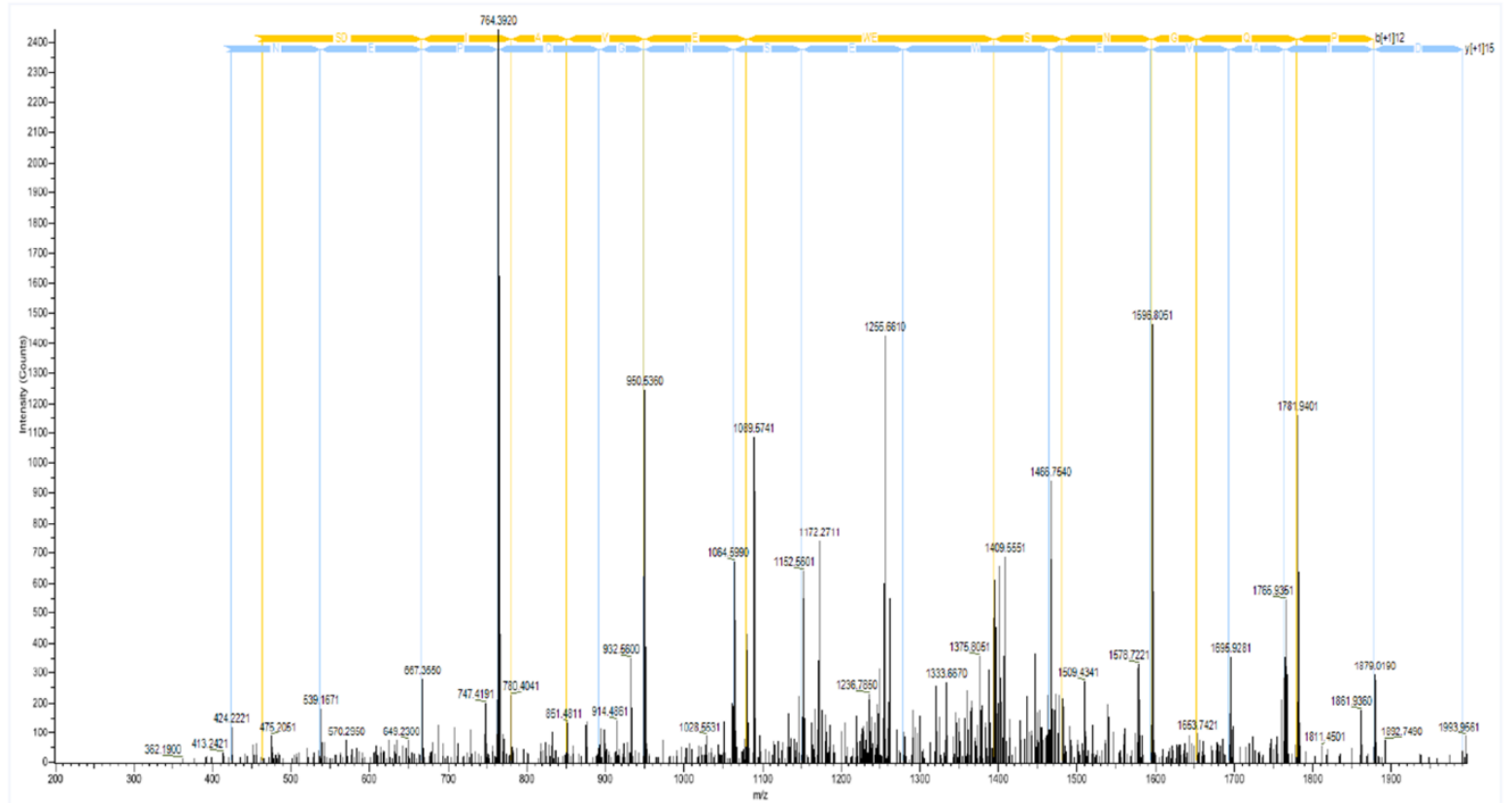

Figure S16. MS/MS sequencing of HC-T37 (which found binding with pFcBP) from trastuzumab. 


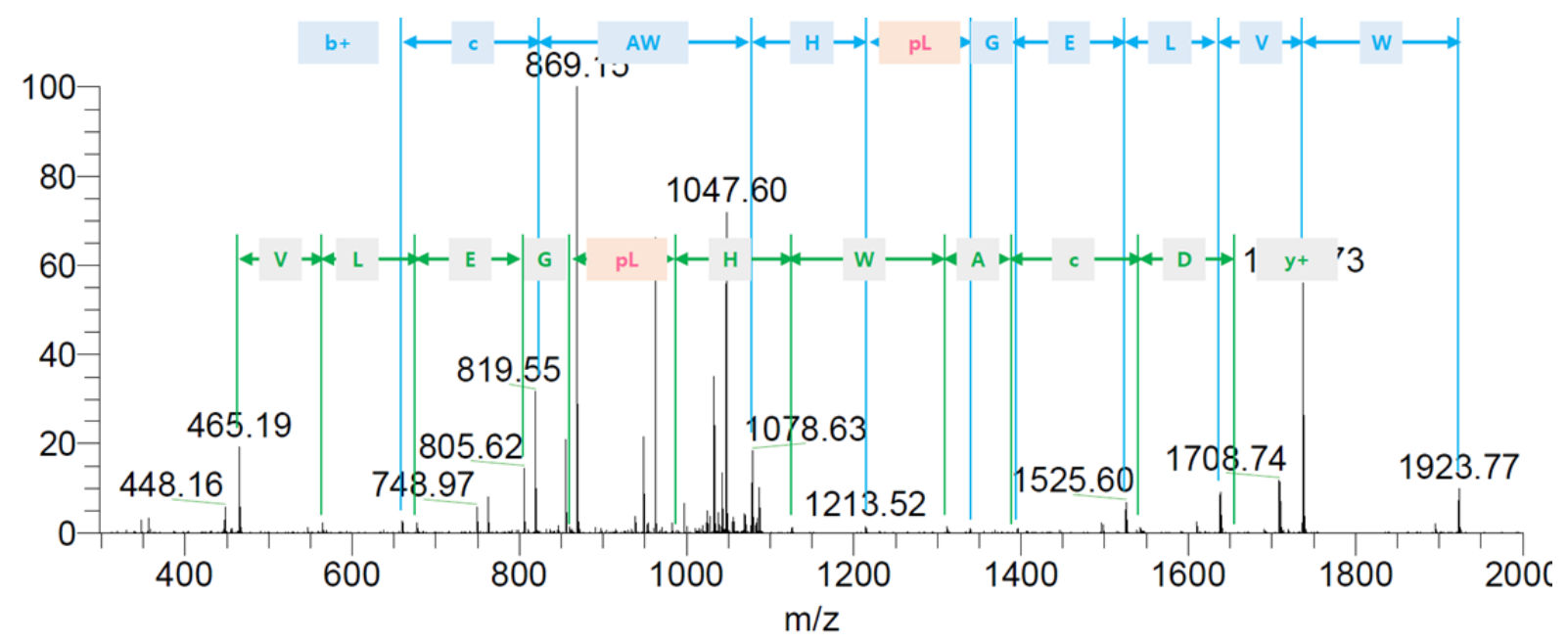

Figure S17. MS/MS sequencing of $\mathrm{pFcBP}$.

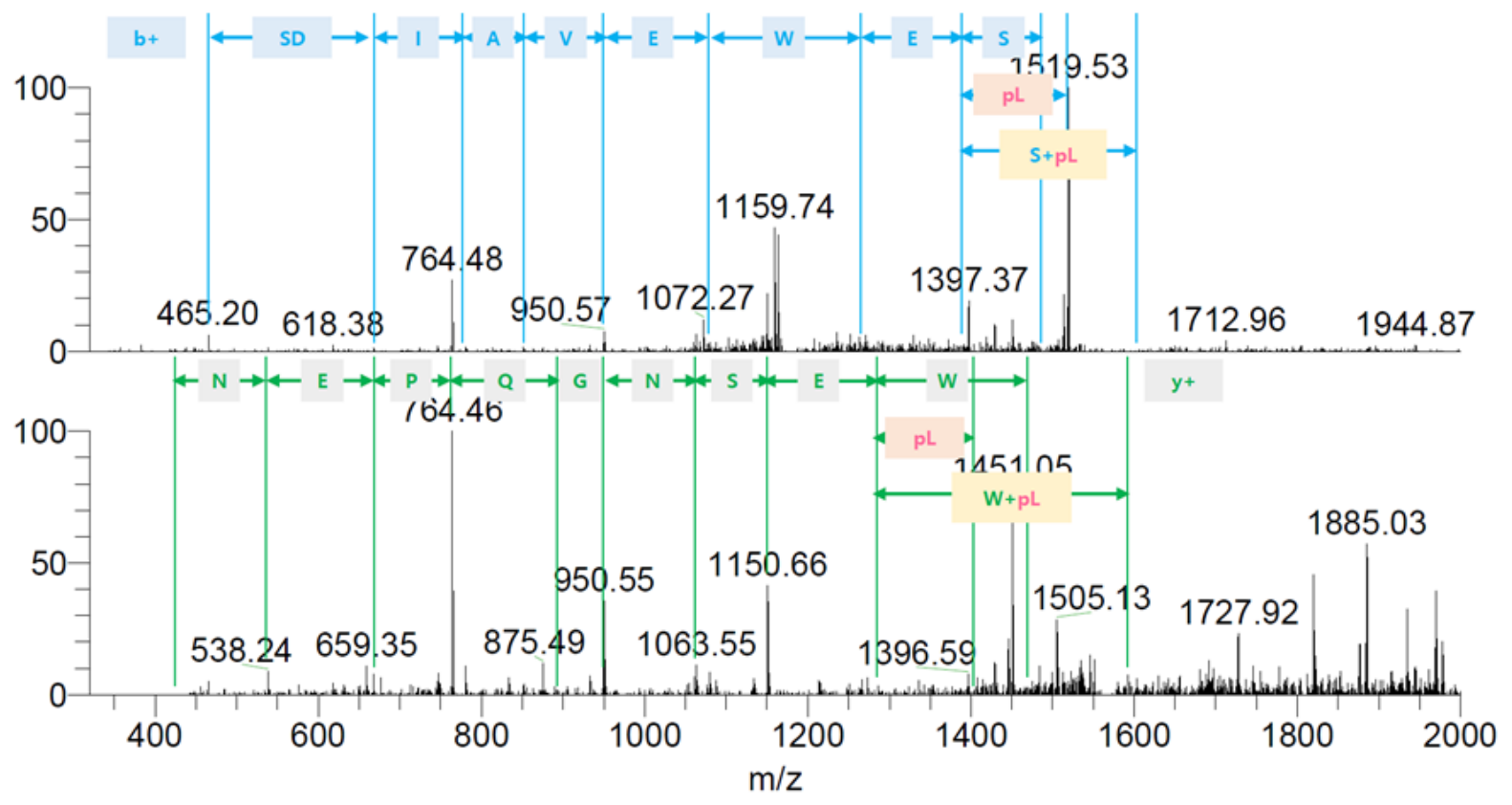

Figure S18. MS/MS sequencing of HC-T37 conjugated with pFcBP from PAR 2. 